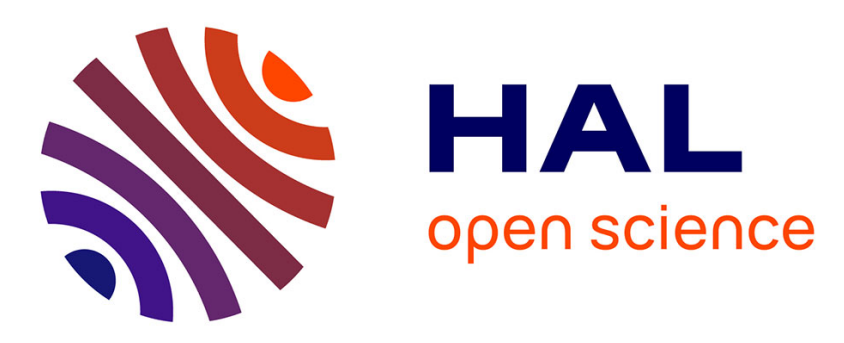

\title{
Highly Luminescent Europium-Based Heteroleptic Coordination Polymers with Phenantroline and Glutarate Ligands
}

\author{
Roza Maouche, Sabrina Belaid, Belkacem Benmerad, Sofiane Bouacida, Carole \\ Daiguebonne, Yan Suffren, Stéphane Freslon, Kevin Bernot, Olivier Guillou
}

\section{To cite this version:}

Roza Maouche, Sabrina Belaid, Belkacem Benmerad, Sofiane Bouacida, Carole Daiguebonne, et al.. Highly Luminescent Europium-Based Heteroleptic Coordination Polymers with Phenantroline and Glutarate Ligands. Inorganic Chemistry, 2021, 60 (6), pp.3707-3718. 10.1021/acs.inorgchem.0c03417 . hal-03157353

\section{HAL Id: hal-03157353 https://hal.science/hal-03157353}

Submitted on 26 May 2021

HAL is a multi-disciplinary open access archive for the deposit and dissemination of scientific research documents, whether they are published or not. The documents may come from teaching and research institutions in France or abroad, or from public or private research centers.
L'archive ouverte pluridisciplinaire HAL, est destinée au dépôt et à la diffusion de documents scientifiques de niveau recherche, publiés ou non, émanant des établissements d'enseignement et de recherche français ou étrangers, des laboratoires publics ou privés. 


\section{Highly luminescent europium-based heteroleptic coordination polymers with phenantroline and glutarate ligands.}

Roza Maouche ${ }^{\mathrm{a}}$, Sabrina Belaid ${ }^{\mathrm{a} *}$, Belkacem Benmerad ${ }^{\mathrm{a}}$, Sofiane Bouacida $^{\mathrm{b}, \mathrm{c}}$, Carole Daiguebonne ${ }^{\mathrm{d}}$, Yan Suffren ${ }^{\mathrm{d}}$, Stéphane Freslon ${ }^{\mathrm{d}}$, Kevin Bernot ${ }^{\mathrm{d}}$ and Olivier Guillou ${ }^{\mathrm{d}^{*}}$.

${ }^{a}$ Laboratoire de Physico-Chimie des Matériaux et Catalyse, Faculté des Sciences Exactes, Université de Bejaia, 06000 Bejaia, Algérie.

${ }^{\mathrm{b}}$ Département Sciences de la matière, Faculté des Sciences exactes et Sciences de la nature et de la vie, Université Larbi Ben M’hidi, 4056 Oum El Bouaghi, Algérie.

${ }^{c}$ Unité de Recherche de Chimie de l'Environnement et Moléculaire Structurale, CHEMS, Université des frères Mentouri, Constantine 1, 25000, Algérie.

d Univ Rennes, INSA Rennes, CNRS UMR 6226 "Institut des Sciences Chimiques de Rennes", F-35000 Rennes, France.

* To whom correspondence should be addressed. 


\section{ABSTRACT}

Iso-structural lanthanide-based coordination polymers with general chemical formula $\left[\mathrm{Ln}(\text { phen })(\mathrm{glu})\left(\mathrm{NO}_{3}\right)\right]_{\infty}$ with $\mathrm{Ln}=\mathrm{La}-\mathrm{Tm}$ (except $\mathrm{Ce}$ and $\left.\mathrm{Pm}\right)$ have been synthesized by hydrothermal methods $\left(\mathrm{H}_{2} \mathrm{glu}\right.$ stands for glutaric acid and phen for 1,10-phenantroline). They crystallize in the monoclinic system with $P 2{ }_{1} / c\left(n^{\circ} 14\right)$ space group. The crystal structure has been solved on the basis of the La-derivative. It can be described as the superimposition of molecular chains of dimeric $\mathrm{La}(\mathrm{phen})\left(\mathrm{NO}_{3}\right)-\mathrm{La}(\mathrm{phen})\left(\mathrm{NO}_{3}\right)$ units bridged by glutarate ligands. Luminescent properties have been explored and evidence that the Eu-derivative exhibits the highest luminance observed for Eu-based coordination polymers (85 to 105 cd. $\mathrm{m}^{-2}$ ). Effects of the dilution of the $\mathrm{Eu}^{3+}$ and $\mathrm{Tb}^{3+}$ luminescent ions by $\mathrm{Gd}^{3+}$ optically inactive ions are unexpected and to the best of our knowledge unprecedented. This could be relied to the different intermetallic energy transfer mechanisms in competition and to the non-isotropic distribution of the lanthanide ions in these molecular alloys. The investigation of molecular alloys with general chemical formula $\left[\mathrm{Eu}_{1-x} \mathrm{~Tb}_{x}(\text { phen })(\mathrm{glu})\left(\mathrm{NO}_{3}\right)\right]_{\infty}$ with $0 \leq x \leq 1$ highlights a very sizeable and constant $\mathrm{Eu}^{3+}$ luminescence whatever the $x$ value that further confirm the existence of very strong intermetallic energy transfers in this family of compounds. It is also noticeable that some coordination polymers based on weakly emissive lanthanide ions exhibit very well defined emission spectra.

\section{KEYWORDS.}

Phenantroline, Glutaric acid, Lanthanides coordination polymers, Single-crystal, Photoluminescence. 


\section{INTRODUCTION.}

For more than a decade, lanthanide-based coordination polymers ${ }^{1}$ have attracted a growing interest because of their interesting optical properties. ${ }^{2-5}$ Indeed, they can find their application in various technological fields such as molecular thermometry, ${ }^{6-8}$ lighting and display, ${ }^{4,-10}$ chemical sensing ${ }^{11-15}$ or fight against counterfeiting. ${ }^{16-17}$

Most lanthanide ions exhibit luminescent properties. However, their molar absorptivity is weak and their direct excitation is inefficient. ${ }^{18}$ This can be overcame thanks to the so-called "antenna effect"19 that consists on exciting the ligand that then transfers its energy to the lanthanide ion that finally de-excites by emitting a photon. This mechanism, which is widely used in lanthanide coordination chemistry, ${ }^{20-22}$ requires a ligand with as high as possible molar absorptivity.

It is also commonly admitted that long intermetallic distances favors lanthanides luminescence by reducing the intermetallic quenching. ${ }^{23-24}$ Therefore, in one hand, using long ligands with extended conjugation, and therefore high molar absorption, looks like a promising strategy as far as highly luminescent lanthanide-based coordination polymers are targeted. In the other hand, extended conjugation provokes a red-shift of the absorption band of the ligand that, therefore, can overlap the lanthanides $4 \mathrm{f}-4 \mathrm{f}$ transitions and prevent their sensitization by antenna effect. ${ }^{25}$

Additionally, non-radiative de-excitation of the lanthanide ions, especially that of $\mathrm{Eu}^{3+}$ ions is very sensitive to the high energy $\mathrm{O}-\mathrm{H}$ or $\mathrm{C}-\mathrm{H}$ vibrators in the vicinity of the lanthanide ions ${ }^{18}$ and more generally a rigid molecular framework favors lanthanide luminescence. ${ }^{26}$

Most often, only one ligand is used for the absorption of the excitation radiation as well as for connecting the lanthanide ions. Therefore, its choice is commonly a compromise between the constraints listed above. ${ }^{9,} 27-30$

In this study, two different ligands were used: One acts as an "antenna" and the other 
one as a connector. It has previously been evidenced that 1,10-phenantroline (phen) is efficient as far as "antenna effect" is concerned. Moreover, this bulky ligand prevents solvent molecules from entering in the lanthanide coordination sphere. ${ }^{31-32}$ Therefore 1,10-phenantroline has been chosen for acting both as an antenna and as a rigid bulky ligand able to clutter the lanthanide coordination sphere. Glutaric acid $\left(\mathrm{H}_{2} \mathrm{glu}\right)$ is an aliphatic di-carboxylic ligand that is able to connect lanthanide ions to each other and is very flexible. It can easily accommodate for various crystal packing arrangements and fits well with the numerous coordination modes of the lanthanide ions.

To the best of our knowledge, there are only few examples of coordination compounds based on the ternary system $\mathrm{Ln}^{3+} /$ phen/ $\mathrm{H}_{2}$ glu: compounds that constitute the first reported structural family have general chemical formula $\left[\operatorname{Ln}_{2}(\text { phen })_{2}(\text { glu })_{3}\right]_{\infty}$ with $\mathrm{Ln}=\mathrm{Ce}-\mathrm{Yb} ;{ }^{33-38}$ the second structural family gathers coordination polymers with general chemical formula $[\mathrm{Ln}(\mathrm{glu})(\mathrm{phen}) \mathrm{Cl}]_{\infty}$ with $\mathrm{Ln}=\mathrm{Tb}, \mathrm{Ho}, \mathrm{Tm}$ and $\mathrm{Y} ;{ }^{34,37}$ the last structural family has, to date, only one membership: $\left[\mathrm{Pr}(\mathrm{Hglu})(\mathrm{glu})(\mathrm{phen}) \cdot 2 \mathrm{H}_{2} \mathrm{O}\right]_{\infty} .{ }^{39}$ All the three crystal structures present bidentate phen ligands that protect dimeric lanthanide units bound to each other by $\mathrm{glu}^{2-}$ ligands. However, luminescence data are very scarce and only the optical properties of $\left[\operatorname{Pr}(\mathrm{Hglu})(\mathrm{glu})(\mathrm{phen}) \cdot 2 \mathrm{H}_{2} \mathrm{O}\right]_{\infty} .^{39}$ and $\left[\mathrm{Ln}_{2}(\text { phen })_{2}(\mathrm{glu})_{3}\right]_{\infty}{ }^{33}$ have been studied in details. Moreover no hetero-lanthanide compound (also called molecular alloy ${ }^{40}$ ) has been prepared.

This paper deals with the structural and luminescence studies of a large family of heteroleptic isostructural compounds that gathers homo- and hetero-lanthanide compounds.

\section{EXPERIMENTAL SECTION}

Lanthanide oxides $(4 \mathrm{~N})$ were purchased from Ampere Company and used without further purification. The nitrates were prepared according to established procedures. ${ }^{41}$ 1,10-phenantroline and glutaric acid were purchased from TCI and used without further 
purification.

\section{Synthesis of the lanthanide-based coordination polymers.}

$0.11 \mathrm{mmol}$ of a hydrated lanthanide nitrate, $0.11 \mathrm{mmol}$ of 1,10 -phenantroline monohydrate, $0.17 \mathrm{mmol}$ of glutaric acid and $10 \mathrm{~mL}$ of deionized water were mixed. The $\mathrm{pH}$ value was adjusted to about 5 with few drops of an aqueous solution of $\mathrm{NaOH}\left(0.5\right.$ mol. $\left.\mathrm{L}^{-1}\right)$. After stirring for 1 hour, the mixture was placed in a Teflon-lined stainless-steel autoclave (25 mL), and heated at $170^{\circ} \mathrm{C}$ for two days under autogenous pressure. Upon cooling to room temperature, yellow single crystals suitable for single-crystal X-ray diffraction were obtained. They were washed with distilled water and dried under ambient temperature and pressure. All the compounds were assumed to be iso-structural on the basis of their powder X-ray diffraction pattern realized on crushed single crystals (Figure S1).

Hetero-lanthanide coordination polymers have been prepared according to a similar procedure just replacing the lanthanide nitrate aqueous solution by an aqueous solution of the appropriate mixture of lanthanide nitrates. ${ }^{42}$ Three series of hetero-lanthanide coordination polymers have been prepared: $\left[\mathrm{Tb}_{1-x} \mathrm{Eu}_{x}(\text { phen })(\mathrm{glu})\left(\mathrm{NO}_{3}\right)\right]_{\infty},\left[\mathrm{Tb}_{1-x} \mathrm{Gd}_{x}(\text { phen })(\mathrm{glu})\left(\mathrm{NO}_{3}\right)\right]_{\infty}$ and $\left[\mathrm{Gd}_{1-x} \mathrm{Eu}_{x}(\text { phen })(\mathrm{glu})\left(\mathrm{NO}_{3}\right)\right]_{\infty}$ with $0 \leq x \leq 1$. On the basis of their powder $\mathrm{X}$-ray diffraction patterns it has been assumed that they are all iso-structural to the homo-lanthanide derivatives (Figures S2 to S4). Relative metallic contents have been estimated by EDS measurements (Tables S1 to S3). The random character of the distribution of the lanthanide ions over the metallic sites has been assumed on the basis of previously reported data on similar compounds. $^{22,43}$ 


\section{X-ray diffraction.}

Experimental diagrams of powder X-ray diffraction have been collected with an analytical X'pert Pro diffractometer equipped with an X'Celerator detector (45 kV, $40 \mathrm{~mA}$ for $\operatorname{CuK} \alpha(\lambda=1.542 \AA)$ in $\theta / \theta$ mode $)$. Calculated diagrams were produced using Powdercell ${ }^{44}$ and WinPLOTR ${ }^{45}$ programs.

Single-crystal X-ray diffraction data were collected at 295(2) K on a Bruker D8 Venture diffractometer equipped with a PHOTON 100 CMOS area detector with graphite monochromatic $\mathrm{MoK} \alpha$ radiation $(\lambda=0.71073 \AA), \theta$ range $\left(2.46-29.08^{\circ}\right)$. The crystal structure has been solved on the basis of the lanthanum-derivative.

Absorption corrections were performed on the basis of multi-scan method. ${ }^{46}$ Crystal structure was solved through direct methods with the program SIR-9747 and refined with SHELXL $^{48}$ program using full-matrix least-squares methods on $\mathrm{F}^{2}$ procedure within the WinGX software package. ${ }^{49}$ All non-hydrogen atoms were refined anisotropically. Hydrogen atoms were located at ideal positions. A summary of the crystal and final structure refinement data of $\left[\mathrm{La}(\mathrm{phen})(\mathrm{glu})\left(\mathrm{NO}_{3}\right)\right]_{\infty}$ are listed in Table 1 and selected bond distances $(\AA)$ and angles $\left({ }^{\circ}\right)$ in Table S4. 


\begin{tabular}{ll}
\hline \multicolumn{2}{l}{ Table 1. Final structure refinement data for $\left[\mathrm{La}(\mathrm{phen})(\mathrm{glu})\left(\mathrm{NO}_{3}\right)\right]_{\infty}}$. \\
\hline Molecular formula & $\mathrm{La}_{4} \mathrm{O}_{28} \mathrm{~N}_{12} \mathrm{C}_{68} \mathrm{H}_{56}$ \\
Formula weight $\left(\mathrm{g} . \mathrm{mol}^{-1}\right)$ & 2044.88 \\
System & Monoclinic \\
Space Group & $P 2_{1} / c\left(\mathrm{n}^{\circ} 14\right)$ \\
$a(\AA)$ & $8.7588(1)$ \\
$b(\AA)$ & $15.8179(2)$ \\
$c(\AA)$ & $13.6753(2)$ \\
$\beta\left({ }^{\circ}\right)$ & $108.888(1)$ \\
$V\left(\AA^{3}\right)$ & $1792.63(4)$ \\
$Z$ & 4 \\
$D_{c}\left(\mathrm{~g} . \mathrm{cm}^{-3}\right)$ & 1.894 \\
$T(\mathrm{~K})$ & $293(2)$ \\
$F(000)$ & 1000 \\
$\mu(\mathrm{Mo}-\mathrm{K} \alpha)\left(\mathrm{mm}^{-1}\right)$ & 2.430 \\
$\theta$ range for data collection $\left(^{\circ}\right)$ & $2.46-29.08$ \\
$R_{1}(\%)$ & 2.66 \\
$w R_{2}(\%)$ & 5.65 \\
$S$ & 1.057 \\
Reflections & 4919 \\
Parameters & 253 \\
CCDC $\mathrm{n}^{\circ}$ & 2003004 \\
\hline
\end{tabular}

\section{Infrared spectroscopy}

IR spectra were recorded on a Perkin-Elmer Spectrum II model FT-IR spectrophotometer using ATR method in the $4000-400 \mathrm{~cm}^{-1}$ range, with a resolution of $4 \mathrm{~cm}^{-1}$ at room temperature. All the spectra were identical and only the one of the lanthanum-derivative is reported (Figure S5), as a matter of example. This spectrum exhibits intense peaks around $1519-1576 \mathrm{~cm}^{-1}$ and $1402-1457 \mathrm{~cm}^{-1}$ that can be attributed to asymmetric and symmetric stretching vibrations of the $\mathrm{COO}^{-}$group, respectively. ${ }^{50}$ It confirms that the two carboxylic functions of the glutaric acid are deprotonated. The weak band centered at $3065 \mathrm{~cm}^{-1}$ corresponds to $v(\mathrm{CH})$ stretching vibrations, the two sharp peaks at 723 and $832 \mathrm{~cm}^{-1}$ correspond to the $\delta(\mathrm{CH})$ out of the plane bending vibrations, whereas the in-plane vibration is observed at $1027 \mathrm{~cm}^{-1}$, which is in agreement with the presence of the phen ligand. ${ }^{50-52}$ The small shoulders around 2942 and $2971 \mathrm{~cm}^{-1}$ correspond to $v_{\text {sym }}$ and $v_{\text {asym }}$ of C-H groups of the glutarate ligand. At low wavenumber (around $415 \mathrm{~cm}^{-1}$ ), this spectrum 
shows vibration frequencies of the $\mathrm{La}-\mathrm{N}$ and $\mathrm{La}-\mathrm{O}$ bonds, confirming the coordination of glu $^{2-}$ and phen ligands. ${ }^{53}$

\section{Energy Dispersive Spectroscopy measurements}

Energy-Dispersive Spectroscopy (EDS) measurements have been performed with a Hitachi TM-1000 Tabletop Microscope version 02.11 (Hitachi High-Technologies, Corporation, Tokyo, Japan) with EDS analysis system (SwiftED-TM, Oxford Instruments Link INCA). All EDS measurements were performed several times on several particles in order to insure reproducibility and to confirm the chemical homogeneity of the powders.

\section{Thermal analyses}

Thermo-gravimetric and thermo-differential measurements (TG/TD) were carried out in platinum crucibles from room temperature to $970^{\circ} \mathrm{C}$ under nitrogen atmosphere with a $5^{\circ} \mathrm{C} \cdot \mathrm{min}^{-1}$ heating rate, using a Perkin-Elmer Pyris-Diamond thermal analyzer. At the end of the experiments, the compounds were maintained for $1 \mathrm{~h}$ at $970^{\circ} \mathrm{C}$ under synthetic air in order to complete the combustion. All the thermal analyses were similar and only the one of the lanthanum-derivative is reported (Figure S6). It shows a high thermal stability up to $330^{\circ} \mathrm{C}$, followed by a continuous weight loss (between 330 and $900^{\circ} \mathrm{C}$ ) that corresponds to the complete decomposition of ligand (observed weight loss is $69.45 \%$ (calcd: $68.14 \%$ )). The final residue (30.80\% - calcd: $31.86 \%)$ is lanthanum oxide $\left(\mathrm{La}_{2} \mathrm{O}_{3}\right)$.

\section{Optical measurement}

Excitation and emission spectra were recorded in the solid-state on a Horiba Jobin-Yvon Fluorolog III fluorescence spectrometer with a continuous Xe lamp (450 W) equipped with an UV-Vis photomultiplier (PMT Hamamatsu R928, range $=190-860 \mathrm{~nm}$ ) and 
an infrared-photodiode cooled by liquid nitrogen (InGaAs, range $=800-1600 \mathrm{~nm}$ ) or on a Horiba Jobin-Yvon FluoroMax 4 Plus fluorescence spectrometer equipped with a Xe lamp $(150 \mathrm{~W})$ and a UV-Vis photomultiplier (Hamamatsu R928, sensitivity 190-860 nm). Luminescence spectra were recorded at room temperature in the $350-1600 \mathrm{~nm}$ range. Quantum yields were measured using G8 GMP integrating sphere thanks to the following formula: $\Phi=\left(\mathrm{E}_{\mathrm{c}}-\mathrm{E}_{\mathrm{a}}\right) /\left(\mathrm{L}_{\mathrm{a}}-\mathrm{L}_{\mathrm{c}}\right)$ where $\mathrm{E}_{\mathrm{c}}$ and $\mathrm{L}_{\mathrm{c}}$ are the integrated emission spectrum and the absorption at the excitation wavelength of the sample, while $\mathrm{E}_{\mathrm{a}}$ and $\mathrm{L}_{\mathrm{a}}$ are the integrated "blank" emission spectrum and "blank" absorption, respectively. Luminescence decays were measured at room-temperature using a Xenon flash lamp (phosphorescence mode) from the Fluorolog III spectrometer. The luminescence of the La-based microcrystalline powder has been measured at $77 \mathrm{~K}$ : the sample is introduced in a quartz capillary tube, which it is placed inside a small Dewar containing nitrogen liquid. Solid-state emission/excitation spectra and lifetime curves were realized directly on powder samples shaped into pellets. For the quantum yield recordings of, the powder samples are introduced in small capillaries, which were placed inside the integrating sphere. Quantum yields and luminescence decays are averages of two or three independent determinations. Appropriate filters were used to remove the residual excitation laser light, the Rayleigh scattered light and associated harmonics from spectra. All spectra were corrected for the instrumental response function.

Luminance of the samples expressed in $c d . m^{-2}$ have been measured with a Gigahertz-Optik X1-1 optometer with an integration time of $200 \mathrm{~ms}$ on $1.5 \mathrm{~cm}^{2}$ pellets under UV irradiation $\left(\lambda_{\text {exc }}=312 \mathrm{~nm}\right)$. The intensity of the UV flux at sample location is 0.94(2) $\mathrm{mW} . \mathrm{cm}^{-2}$. It has been measured with a VilberLourmat VLX-3W radiometer. $\left[\mathrm{Tb}_{2}(\mathrm{bdc})_{3} \cdot 4 \mathrm{H}_{2} \mathrm{O}\right]_{\infty}$, where bdc ${ }^{2-}$ stands for terephthalate, was used as a standard. It has been synthesized according to an already published procedure. ${ }^{54}$ Its luminance is $94(4) \mathrm{cd} . \mathrm{m}^{-2}$ under these operating conditions $\left(\lambda_{\mathrm{exc}}=312 \mathrm{~nm}\right.$; flux $\left.=0.94(2) \mathrm{mW} \cdot \mathrm{cm}^{-2}\right){ }^{42}$ 
The CIE (Commission Internationale de l'Eclairage) ( $\mathrm{x}$, y) emission color coordinates $^{55-56}$ were measured with a MSU-003 colorimeter (Majantys) equipped with the PhotonProbe 1.6.0 Software (Majantys). Color measurements: $2^{\circ}$, CIE 1931, step 5 nm, under $312 \mathrm{~nm} \quad \mathrm{UV} \quad$ light. $\mathrm{X}=k \times \int_{380 \mathrm{~nm}}^{780 \mathrm{~nm}} I_{\lambda} \times x_{\lambda}, \quad \mathrm{Y}=k \times \int_{380 \mathrm{~nm}}^{780 \mathrm{~nm}} I_{\lambda} \times y_{\lambda} \quad$ and $\quad \mathrm{Z}=k \times$ $\int_{380 \mathrm{~nm}}^{780 \mathrm{~nm}} I_{\lambda} \times z_{\lambda}$ with $\mathrm{k}$ constant for the measurement system, $\mathrm{I} \lambda$ sample spectrum intensity wavelength depending, $\mathrm{x} \lambda, \mathrm{y} \lambda, \mathrm{z} \lambda$ trichromatic values. Mean $\mathrm{xyz}$ values $(\mathrm{x}=\mathrm{X} /(\mathrm{X}+\mathrm{Y}+\mathrm{Z})$, $\mathrm{y}=\mathrm{Y} /(\mathrm{X}+\mathrm{Y}+\mathrm{Z})$ and $\mathrm{z}=\mathrm{Z} /(\mathrm{X}+\mathrm{Y}+\mathrm{Z}))$ are given for each sample, which act as light sources (luminescent samples). Standards from Phosphor Technology used, calibrated at $312 \mathrm{~nm}$ : red phosphor $\mathrm{Gd}_{2} \mathrm{O}_{2} \mathrm{~S}: \mathrm{Eu}(\mathrm{x}=0.667, \mathrm{y}=0.330)$ and green phosphor $\mathrm{Gd}_{2} \mathrm{O}_{2} \mathrm{~S}: \mathrm{Tb}(\mathrm{x}=0.328$, $\mathrm{y}=0.537)$

\section{RESULTS AND DISCUSSION}

\section{Structural description of $\left[\mathrm{La}(\text { phen })(\text { glu })\left(\mathrm{NO}_{3}\right)\right]_{\infty}$}

The crystal structure has been solved on the basis of the lanthanum-containing coordination polymer: $\left[\mathrm{La}(\mathrm{phen})(\mathrm{glu})\left(\mathrm{NO}_{3}\right)\right]_{\infty}$. It crystallizes in the monoclinic system, space group $P 21 / c\left(n^{\circ} 14\right)$. It can be noticed that this crystal structure resemble to the crystal structure of $[\mathrm{Ln}(\mathrm{glu})(\mathrm{phen}) \mathrm{Cl}]_{\infty}$ with $\mathrm{Ln}=\mathrm{Tb}, \mathrm{Ho}, \mathrm{Tm}$ and $\mathrm{Y} .{ }^{34,37}$

The asymmetric unit contains one $\mathrm{La}^{3+}$ ion, one phen ligand, one glutarate ligand and one nitrate ion. The lanthanum ion is nine coordinated by five oxygen atoms from four glutarate ligand, two nitrogen atoms from a phen ligand and two oxygen atoms from one nitrate ion (Figure 1). The coordination polyhedron can be described as a slightly distorted capped trigonal antiprism. The La-O and $\mathrm{La}-\mathrm{N}$ bond lengths are in the ranges 2.4465(2)-2.6701(2) $\AA$ and 2.6834(2)-2.6861(2) A, respectively. The glutarate ligand adopts only one coordination mode (Figure 1). It presents the anti-anti conformation with torsions angles: C21-C22-C23-C24 (174.674(1) $\left.{ }^{\circ}\right)$ and C22-C23-C24-C25 (170.880(1) $\left.{ }^{\circ}\right)$. 


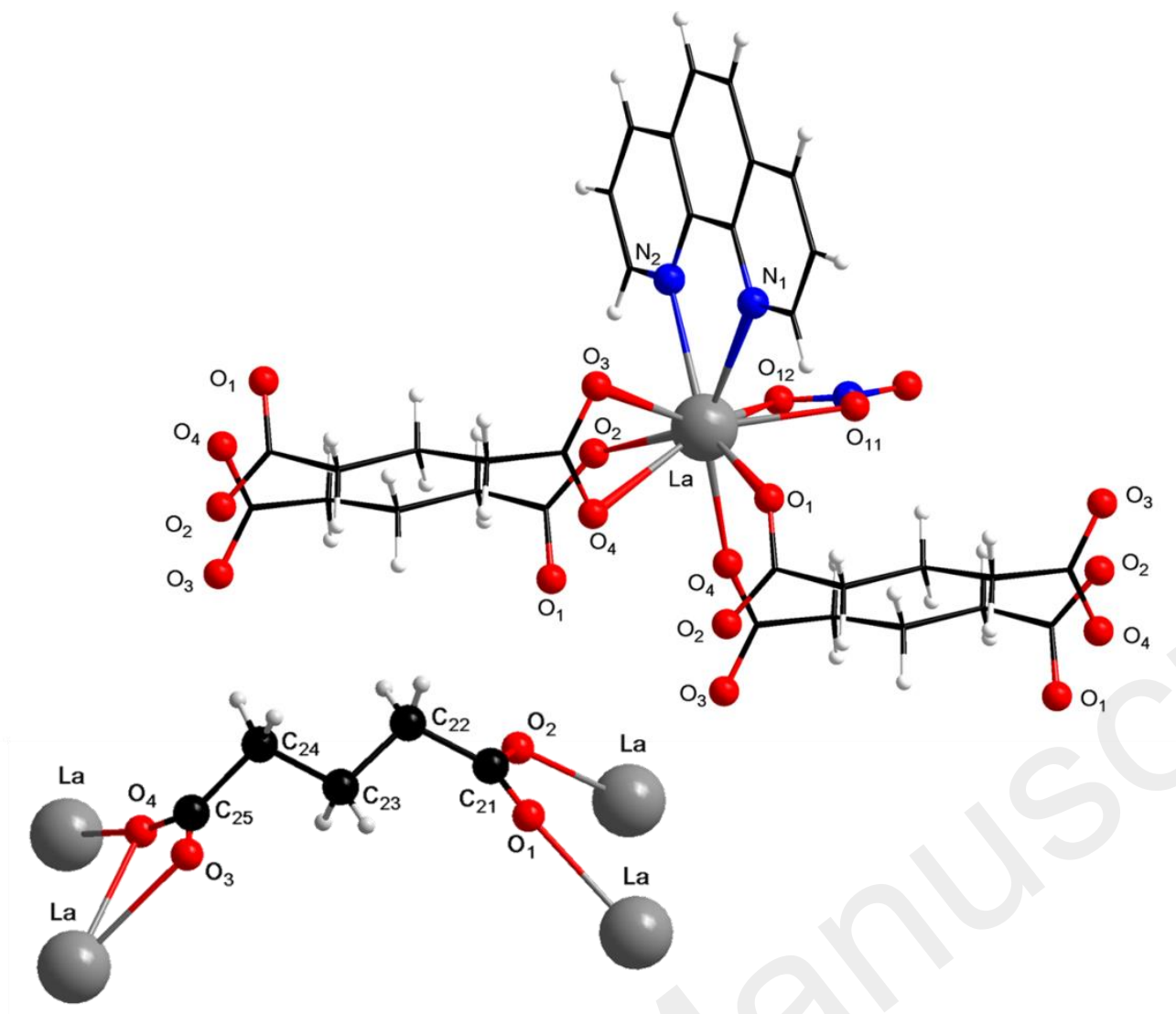

Figure 1. Extended asymmetric unit (top) and glutarate coordination mode (bottom) in $\left[\mathrm{La}(\mathrm{phen})(\mathrm{glu})\left(\mathrm{NO}_{3}\right)\right]_{\infty}$.

The $\mathrm{La}^{3+}$ ions constitute bi-nuclear units in which $\mathrm{La}^{3+}-\mathrm{La}^{3+}$ distance is equal to 4.0320(1) A. The binuclear units consist of two edge-sharing polyhedrons. They are linked to each other by glutarate ligands. The 1D molecular chain spread along the $a$-axis and shortest $\mathrm{La}^{3+}-\mathrm{La}^{3+}$ distances between $\mathrm{La}^{3+}$ ions bridged by glutarate ligands is $8.759(1) \AA$. Shortest intermetallic distances between lanthanide ions that belong to adjacent molecular chains are quite long, that is about $9 \AA$ (Figure 2). A pseudo-two-dimensional network is provided by $\pi$-staking of the aromatic rings of parallel phen ligands with $3.5770(1) \AA$ centroid-to-centroid distance (Figure 3). 


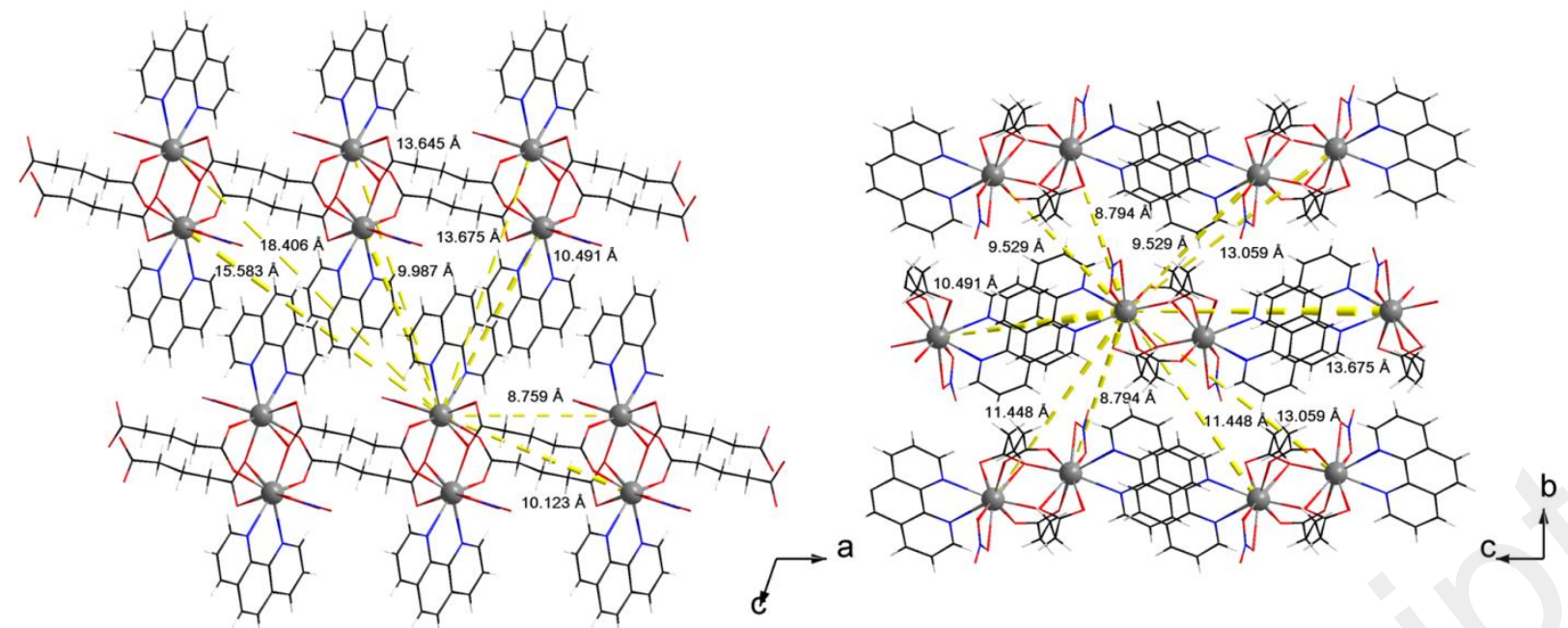

Figure 2. Projection views along the $b$ - and $a$-axes of the crystal packing of $\left[\mathrm{La}(\mathrm{phen})(\mathrm{glu})\left(\mathrm{NO}_{3}\right)\right]_{\infty}$. Intermetallic contacts are symbolized by yellow broken lines. Selected inter-metallic distances are reported.

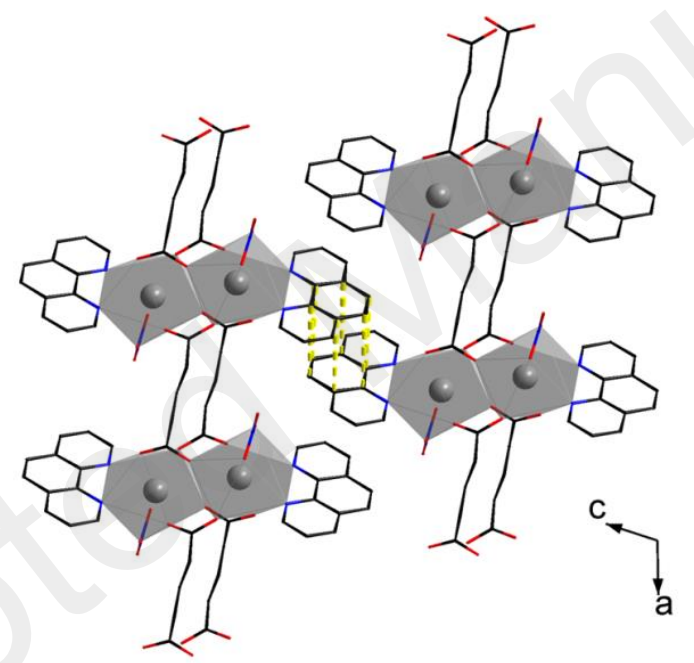

Figure 3. Projection view along the $b$-axis of $\left[\mathrm{La}(\mathrm{phen})(\mathrm{glu})\left(\mathrm{NO}_{3}\right)\right]_{\infty}$. Yellow broken lines symbolize $\pi$-stacking interactions.

The mean intermetallic distance, estimated with the rough model that has previously been developed, ${ }^{30}$ that is twice the radius (r) of the sphere whose volume corresponds to the mean volume occupied by a $\mathrm{La}^{3+}$ ion in the crystal structure $\left(r=\sqrt[3]{\frac{\mathrm{V}}{\mathrm{z}_{3}^{4} \pi}}\right)$, is $9.49 \AA$. This is interesting as far as luminescent properties are targeted because it is commonly admitted that intermetallic energy transfers ${ }^{57-58}$ become less efficient above $10 \AA{ }^{18,}{ }^{23}$ Nevertheless, the 
mean distance is not the only parameter that must be taken into account and it has been demonstrated that the presence of di-nuclear units favors intermetallic energy transfers. ${ }^{21,28,59}$

It can be noticed that, in agreement with thermal analyses, there is no crystallization or coordination water molecule in the crystal structure. This supports the relevance of our synthetic strategy.

\section{Photo-luminescence properties of the homo-metallic coordination polymers.}

\section{$\left[\mathrm{La}(\text { phen })(\mathrm{glu})\left(\mathrm{NO}_{3}\right)\right]_{\infty}$.}

Trivalent lanthanum ions $\left([\mathrm{Xe}] 4 \mathrm{f}^{0}\right)$ present no luminescent properties and therefore optical properties of the $\mathrm{La}^{3+}$-derivatives arise from the ligands electronic properties and in the present case, from the phen ligand. Most often, energy of the first excited singlet state $\left(\mathrm{E}\left({ }^{1} \pi^{*}\right)=370 \mathrm{~nm} \approx 27000 \mathrm{~cm}^{-1}\right)$ can be estimated on the basis of the absorption spectrum (Figure S7) $)^{18,42}$ and energy of the first excited triplet state $\left(\mathrm{E}\left({ }^{3} \pi^{*}\right)=365 \mathrm{~nm} \approx 27400 \mathrm{~cm}^{-1}\right)$ on the basis of the emission spectrum (Figure 4). ${ }^{42,60}$ Obviously, this approach doesn't work here and the luminescence spectrum is probably due to vibronic components of the fluorescence of excited singlet states. This assumption is in agreement with previous works that locate the first excited triplet state of phenantroline around $21500 \mathrm{~cm}^{-1}(465 \mathrm{~nm}) .{ }^{61}$ Therefore, in the present case, the feeding of the emissive lanthanide excited states probably arises from the steady excited states. Indeed, excitation and emission spectra (Figure 4) suggest that the best excitation wavelength is $325 \mathrm{~nm} \approx 30800 \mathrm{~cm}^{-1}$. The emission band can be simulated by five Gaussians with respective maxima $365 \mathrm{~nm}\left(\approx 27400 \mathrm{~cm}^{-1}\right), 376 \mathrm{~nm}\left(\approx 26600 \mathrm{~cm}^{-1}\right), 394 \mathrm{~nm}$ $\left(\approx 25400 \mathrm{~cm}^{-1}\right), 410 \mathrm{~nm}\left(\approx 24400 \mathrm{~cm}^{-1}\right)$ and $440 \mathrm{~nm}\left(22730 \mathrm{~cm}^{-1}\right)$ (Figure 4). In the following, it has been assumed that these five emission bands, and especially the two main ones (centered at $26600 \mathrm{~cm}^{-1}$ and $25400 \mathrm{~cm}^{-1}$ ), that are not observed in the presence of an emitting lanthanide ion, are responsible of the ligand-to-lanthanide energy transfers. 

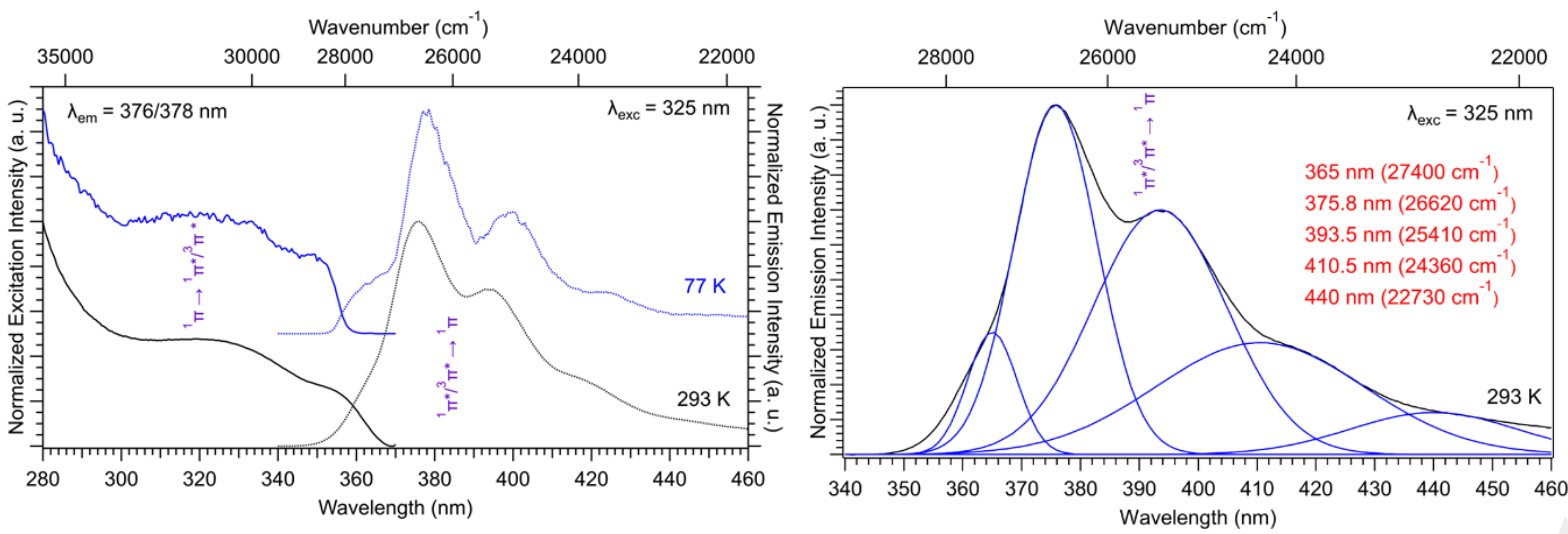

Figure 4. Left: Solid-state excitation and emission spectra of $\left[\mathrm{La}(\mathrm{phen})(\mathrm{glu})\left(\mathrm{NO}_{3}\right)\right]_{\infty}$ recorded at $77 \mathrm{~K}$ (blue curves) and room temperature (dark curves). Right: Room temperature solid-state emission spectrum (dark curve) of $\left[\mathrm{La}(\mathrm{phen})(\mathrm{glu})\left(\mathrm{NO}_{3}\right)\right]_{\infty}$ and its five associated emission bands (blue curves).

Photo-luminescence in the visible and IR domains.

All homo-lanthanide coordination polymers with general chemical formula $\left[\mathrm{Ln}(\text { phen })(\mathrm{glu})\left(\mathrm{NO}_{3}\right)\right]_{\infty}$ with $\mathrm{Ln}=\mathrm{Pr}-\mathrm{Yb}$ except $\mathrm{Pm}$ and $\mathrm{Gd}$ exhibit sizeable luminescence properties in the visible and/or the IR domains. Their excitation and emission spectra have been recorded. They are reported in Figure 5.
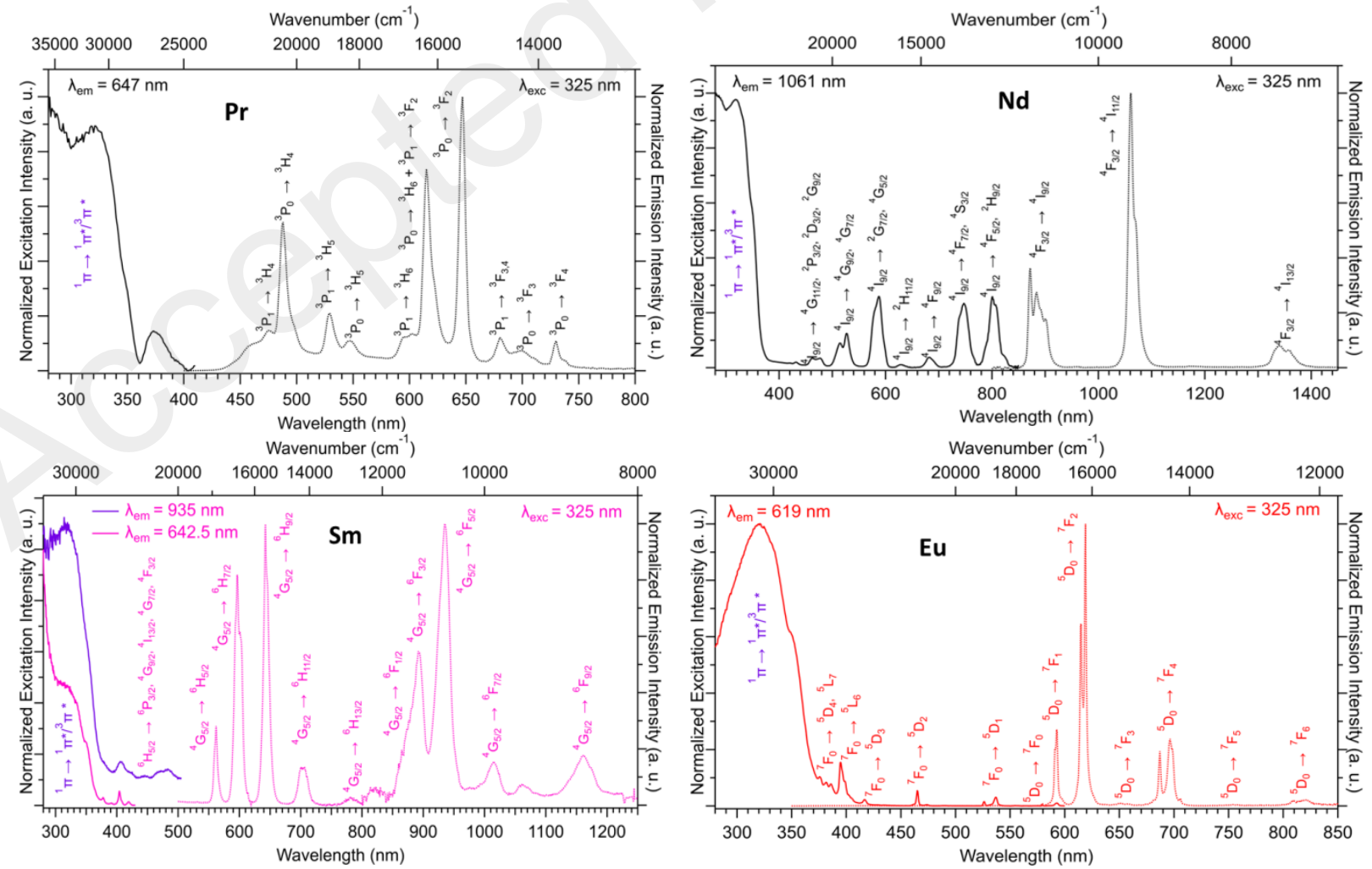

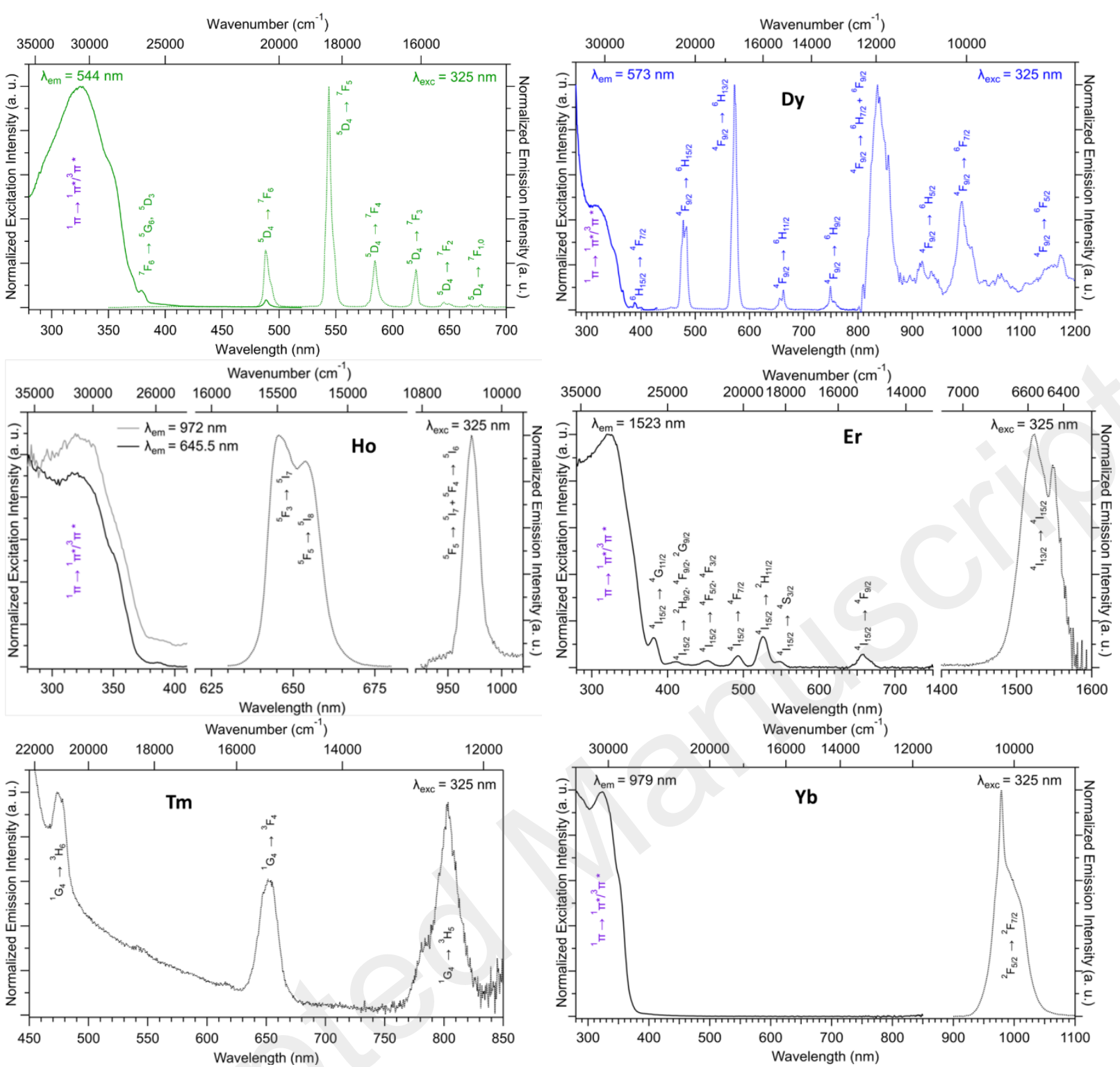

Figure 5. Room temperature solid-state excitation and emission spectra of $\left[\mathrm{Ln}(\text { phen })(\mathrm{glu})\left(\mathrm{NO}_{3}\right)\right]_{\infty}$ with $\mathrm{Ln}=\mathrm{Pr}-\mathrm{Yb}$ except Pm and $\mathrm{Gd}$ in the visible and/or IR domains.

All the excitation spectra show a broad band with a maximum centered at $325 \mathrm{~nm}$ that can be attributed to ${ }^{1} \pi \rightarrow^{1} \pi^{*} /{ }^{3} \pi^{*}$ transitions of the phen ligand. This confirms that the phen ligand acts as an efficient antenna for all the lanthanide ions. From Figure 5, it can be noticed that some of these derivatives exhibit unusually well-defined emission spectra. The $\operatorname{Pr}($ III) and Tm(III) compounds reveal their classical, but rarely observed in the literature for lanthanides-based coordination polymers, emission in the visible. The $\operatorname{Er}(\mathrm{III})$-derivative shows an intense signature of the infrared emission around $1550 \mathrm{~nm}$ valued by the nice 
excitation spectrum where all the f-f transitions from $\operatorname{Er}(\mathrm{III})$ between 380 and $700 \mathrm{~nm}$ are observed.

In the following, we have focused our attention on the $\mathrm{Eu}^{3+}$ - and $\mathrm{Tb}^{3+}$-derivatives. Their overall quantum yields, luminescent lifetimes, colorimetric coordinates and luminance have been measured. They are gathered in Table 2 .

Table 2. Overall quantum yields $\left(\mathrm{Q}_{\mathrm{Ln}}^{\mathrm{Ligand}}\right)$, luminescent lifetimes $\left(\tau_{\mathrm{obs}}\right)$, colorimetric coordinates $(\mathrm{x}, \mathrm{y})$ and luminance of $\left[\mathrm{Ln}(\mathrm{phen})(\mathrm{glu})\left(\mathrm{NO}_{3}\right)\right]_{\infty}$ with $\mathrm{Ln}=\mathrm{Eu}$ and $\mathrm{Tb}$.

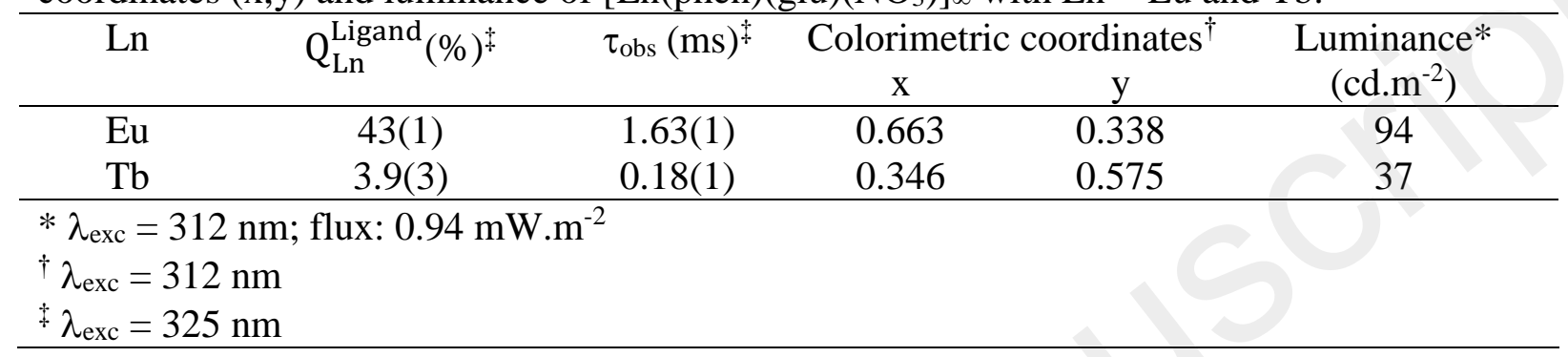

Table 2 shows that the overall quantum yield and the luminescence lifetime of the Eu-derivative are very sizeable, as already observed on coordination polymers based on 1,10-phenantroline derivatives (Table 3). It can be noticed that $\left[\mathrm{Eu}(\mathrm{phen})(\mathrm{glu})\left(\mathrm{NO}_{3}\right)\right]_{\infty}$ presents the longest luminescent lifetime of the compounds listed in Table 3.

Table 3. Reported Eu-based coordination polymers exhibiting high quantum yields.

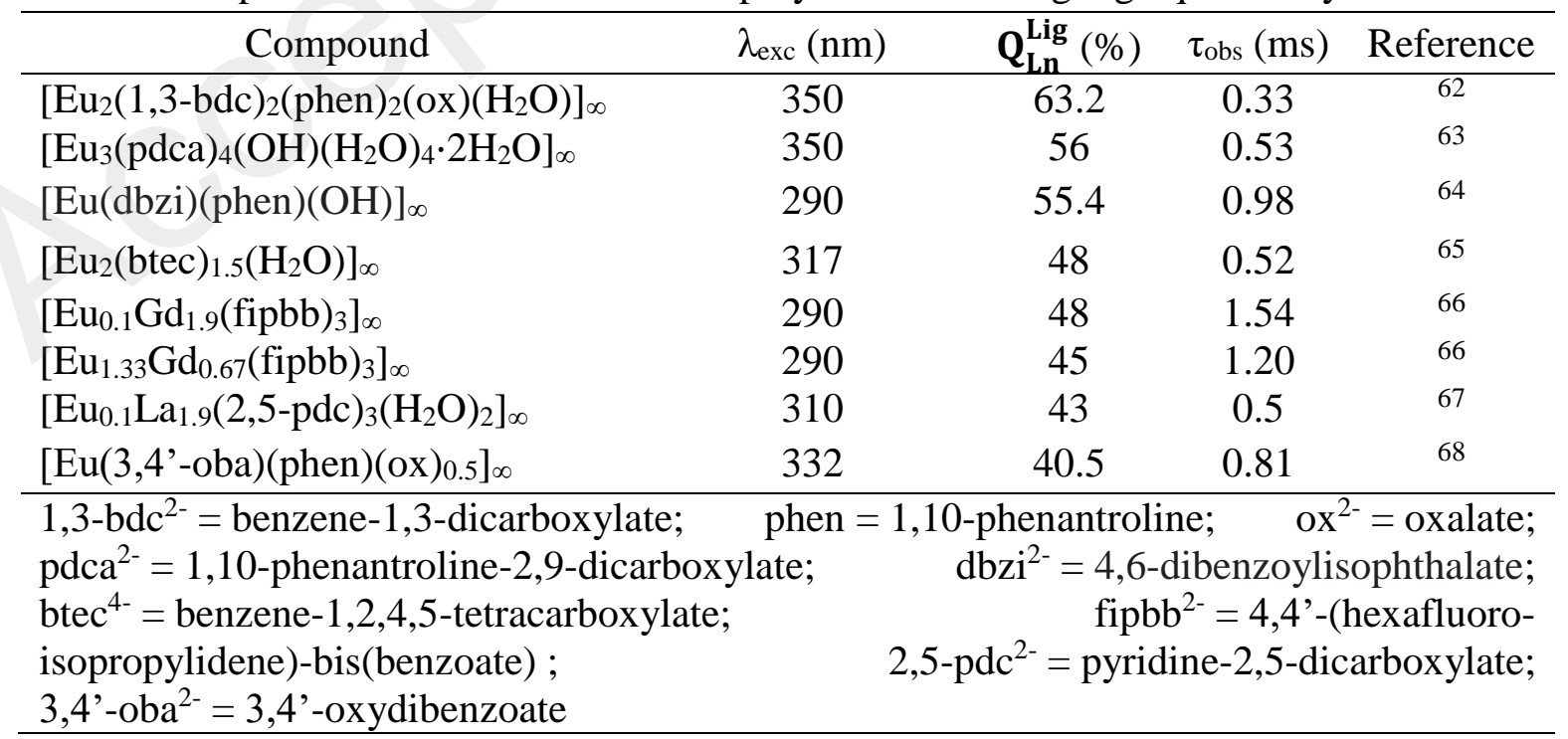


The high overall quantum yield of the Eu-derivative can be related to the absence of high energy vibrators in the vicinity of the $\mathrm{Eu}^{3+}$ ion. ${ }^{18}$ However, this does not explain the weak overall quantum yield of the Tb-derivative.

According to Latva's empirical rules ${ }^{69} \mathrm{Eu}^{3+}$ - and $\mathrm{Tb}^{3+}$-derivatives can accept energy by all their ${ }^{5} \mathrm{D}_{\mathrm{J}}$ levels but significant back-transfer is observed if the energy difference between the ligand excited states and the lanthanide excited levels is too weak $\left(<1850 \mathrm{~cm}^{-1}\right)$. If one assumes, as stated above, that the energies of the feeding excited levels of the ligand are $\approx 27400 \mathrm{~cm}^{-1}, 26600 \mathrm{~cm}^{-1}, 25400 \mathrm{~cm}^{-1}$ and $24400 \mathrm{~cm}^{-1}$, energy transfer from the ligand to the ${ }^{5} \mathrm{D}_{3}\left(\approx 26250 \mathrm{~cm}^{-1}\right)$ excited state of the $\mathrm{Tb}^{3+}$ ion ${ }^{70}$ is probably extremely weak. On the opposite energy transfer to the ${ }^{5} \mathrm{D}_{4}\left(\approx 20400 \mathrm{~cm}^{-1}\right)$ excited state of the $\mathrm{Tb}^{3+}$ ion ${ }^{70}$ is probably weak as well because the energy difference with the excited levels of the ligand is big $\left(>5000 \mathrm{~cm}^{-1}\right)$. These weak energy transfers are in agreement with the very weak overall quantum yield that has been observed for the $\mathrm{Tb}^{3+}$-derivative. (Scheme 1). It can also be noticed that the first excited triplet state is located around $21500 \mathrm{~cm}^{-1}$, that is very close to the ${ }^{5} \mathrm{D}_{4}$ excited state of $\mathrm{Tb}^{3+}$, and could provoke $\mathrm{Tb}$-to-phenantroline energy back-transfer as well. 


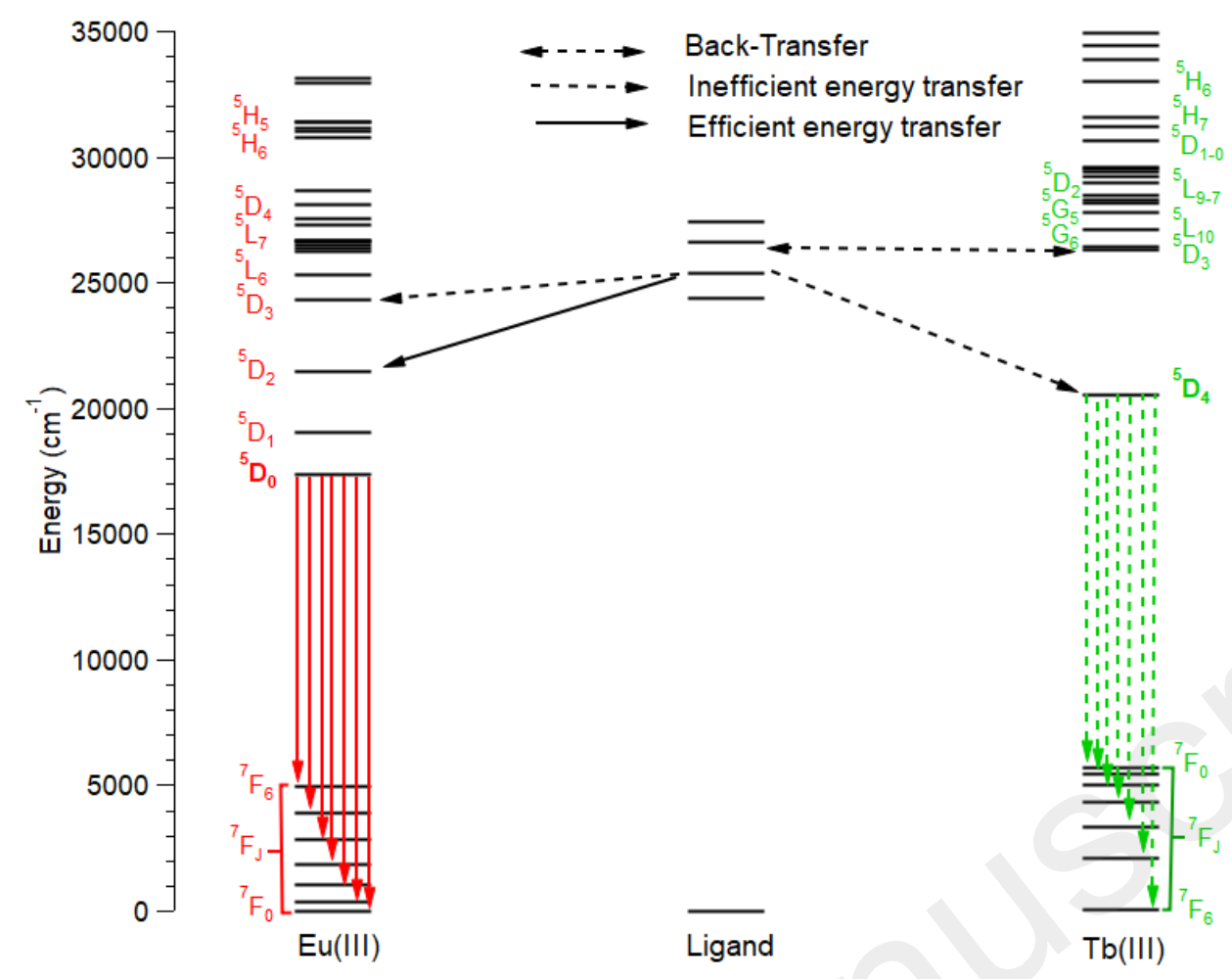

Scheme 1. Suggested ligand-to-lanthanide energy transfer pathways (red full arrows and green dotted arrows correspond to intense and weak emissions from $\mathrm{Eu}^{3+}$ and $\mathrm{Tb}^{3+}$, respectively).

On the opposite, the important overall quantum yield of the Eu-derivative can be related to the energy transfer toward the ${ }^{5} \mathrm{D}_{2}$ excited level $\left(\approx 21450 \mathrm{~cm}^{-1}\right)$ that is expected to be efficient.

Because overall quantum yield and brightness are not directly related ${ }^{26,71}$ we have measured the relative luminance (compared with $\left.\left[\mathrm{Tb}_{2}(\mathrm{bdc})_{3}\left(\mathrm{H}_{2} \mathrm{O}\right)_{4}\right]_{\infty}\right)^{42}$ and the brightness as defined recently by Wong et al. ${ }^{71}$ To the best of our knowledge, $\left[\mathrm{Eu}(\mathrm{phen})(\mathrm{glu})\left(\mathrm{NO}_{3}\right)\right]_{\infty}$ presents the highest values reported to date for an homo-lanthanide Eu-based coordination polymer (Table 4). 
Table 4. Overall quantum yield $\left(Q_{\mathrm{Ln}}^{\mathrm{Ligand}}\right)$ brightness and relative luminance of some reported lanthanide-based coordination polymers.

\begin{tabular}{|c|c|c|c|c|}
\hline Chemical formula & $\begin{array}{c}\text { Relative } \\
\text { luminance }\end{array}$ & Brightness & $\mathrm{Q}_{\mathrm{Ln}}^{\text {Ligand }}(\%)$ & Reference \\
\hline$\left[\mathrm{Tb}_{2}(\mathrm{bdc})_{3}\left(\mathrm{H}_{2} \mathrm{O}\right)_{4}\right]_{\infty} *$ & 1.00 & - & 45.5 & \multirow{2}{*}{42} \\
\hline$\left[\mathrm{Eu}_{2}(\mathrm{bdc})_{3}\left(\mathrm{H}_{2} \mathrm{O}\right)_{4}\right]_{\infty}$ & 0.08 & - & 13.9 & \\
\hline$\left[\mathrm{Eu}_{2}(\mathrm{ip})_{3}\left(\mathrm{H}_{2} \mathrm{O}\right)_{9} \cdot 6 \mathrm{H}_{2} \mathrm{O}\right]_{\infty}$ & 0.04 & - & 10 & 72 \\
\hline$\left[\mathrm{Eu}_{2}(\text { aip })_{2}\left(\mathrm{H}_{2} \mathrm{O}\right)_{10} \text { (aip) } \cdot 4 \mathrm{H}_{2} \mathrm{O}\right]_{\infty}$ & 0.002 & - & - & 73 \\
\hline$\left[\mathrm{Eu}_{2}(\mathrm{hip})_{2}\left(\mathrm{H}_{2} \mathrm{O}\right)_{10}(\mathrm{hip}) \cdot 4 \mathrm{H}_{2} \mathrm{O}\right]_{\infty}$ & $<0.001$ & - & - & 72 \\
\hline$\left[\mathrm{Eu}_{2}(\operatorname{mip})_{3}\left(\mathrm{H}_{2} \mathrm{O}\right)_{8} \cdot 4 \mathrm{H}_{2} \mathrm{O}\right]_{\infty}$ & 0.02 & $0.010(1)$ & 3.6 & 21 \\
\hline$\left[\mathrm{Eu}_{4}(\mathrm{btec})_{3}\left(\mathrm{H}_{2} \mathrm{O}\right)_{15} \cdot 9 \mathrm{H}_{2} \mathrm{O}\right]_{\infty}$ & 0.04 & - & 7.7 & 60 \\
\hline$\left[\mathrm{Eu}(\mathrm{cpbOH})\left(\mathrm{H}_{2} \mathrm{O}\right)_{2}(\mathrm{cpb})\right]_{\infty}$ & 0.02 & $0.011(1)$ & 6.4 & 43 \\
\hline$\left[\mathrm{Eu}_{2}(\mathrm{oba})_{3}\left(\mathrm{H}_{2} \mathrm{O}\right)_{5.5} \cdot 0.5 \mathrm{H}_{2} \mathrm{O}\right]_{\infty}$ & 0.02 & - & 3.2 & 30 \\
\hline$\left[\mathrm{Eu}_{2}(\mathrm{dcpa})_{3}\left(\mathrm{H}_{2} \mathrm{O}\right)\right]_{\infty}$ & 0.36 & $0.14(1)$ & 28 & 74 \\
\hline$\left[\mathrm{Eu}(\mathrm{phen})(\mathrm{glu})\left(\mathrm{NO}_{3}\right)\right]_{\infty}$ & 1.00 & $0.32(1)$ & 43 & This work \\
\hline \multicolumn{5}{|c|}{$\begin{array}{l}\text { bdc }^{2-}=\text { benzene-di-carboxylate; } \quad \mathrm{ip}^{2-}=\text { isophthalate; } \quad \text { aip }{ }^{2-}=\text { amino-isophthalate; hip } \mathrm{p}^{2-}=\text { hydroxy-isophthalate; } \\
\mathrm{mip}^{2-}=\text { methoxy-isophthalate; } \quad \text { btec }^{4-}=\text { benzene-tetra-carboxylate; } \quad \mathrm{cpb}^{2-}=\text { benzene-carboxy-boronate; } \\
\text { oba }^{2-}=\text { oxy-bis(benzoate); dcpa }\end{array}$} \\
\hline
\end{tabular}

\section{Dilution effect: $\left[\mathrm{Eu}_{1-x} \mathbf{G d}_{x}(\right.$ phen $)($ glu $\left.)\left(\mathrm{NO}_{3}\right)\right]$ and $\left[\mathrm{Tb}_{-x} \mathbf{G d}_{x}(\right.$ phen $\left.)(g l u)\left(\mathrm{NO}_{3}\right)\right]$ with}

$\mathbf{0} \leq x \leq 1$

It is well known that dilution of the emissive lanthanide ions by optically inactive ones can reduce intermetallic energy transfers and produce an enhancement of the luminescence intensity, sometimes drastically. ${ }^{26},{ }^{74}$ The high luminescence intensity of $\left[\mathrm{Eu}(\mathrm{phen})(\mathrm{glu})\left(\mathrm{NO}_{3}\right)\right]_{\infty}$ encouraged us to study the dilution effect for this series of compounds. Two series of molecular alloys with respective chemical formula $\left[\mathrm{Eu}_{1-x} \mathrm{Gd}_{x}(\right.$ phen $\left.)(\mathrm{glu})\left(\mathrm{NO}_{3}\right)\right]$ and $\left[\mathrm{Tb}_{1-x} \mathrm{Gd}_{x}(\right.$ phen $\left.)(\mathrm{glu})\left(\mathrm{NO}_{3}\right)\right]$ with $0 \leq x \leq 1$ have been prepared and characterized (Figures S3 and S4; Tables S2 and S3). Their emission spectra $\left(\lambda_{\text {exc }}=325 \mathrm{~nm}\right)$ have been recorded and are reported in Figure 6 . Luminance of the compounds with general chemical formula $\left[\mathrm{Eu}_{1-x} \mathrm{Gd}_{x}(\text { phen })(\mathrm{glu})\left(\mathrm{NO}_{3}\right)\right]_{\infty}$ has been measured $\left(\lambda_{\text {exc }}=312 \mathrm{~nm}\right.$; flux $\left.=94 \mathrm{~mW} \cdot \mathrm{cm}^{-2}\right)$ and shows that the luminance is almost constant and very high (comprised between 83 and $104 \mathrm{~cd} . \mathrm{m}^{-2}$ ) over the whole series (Table S5). 

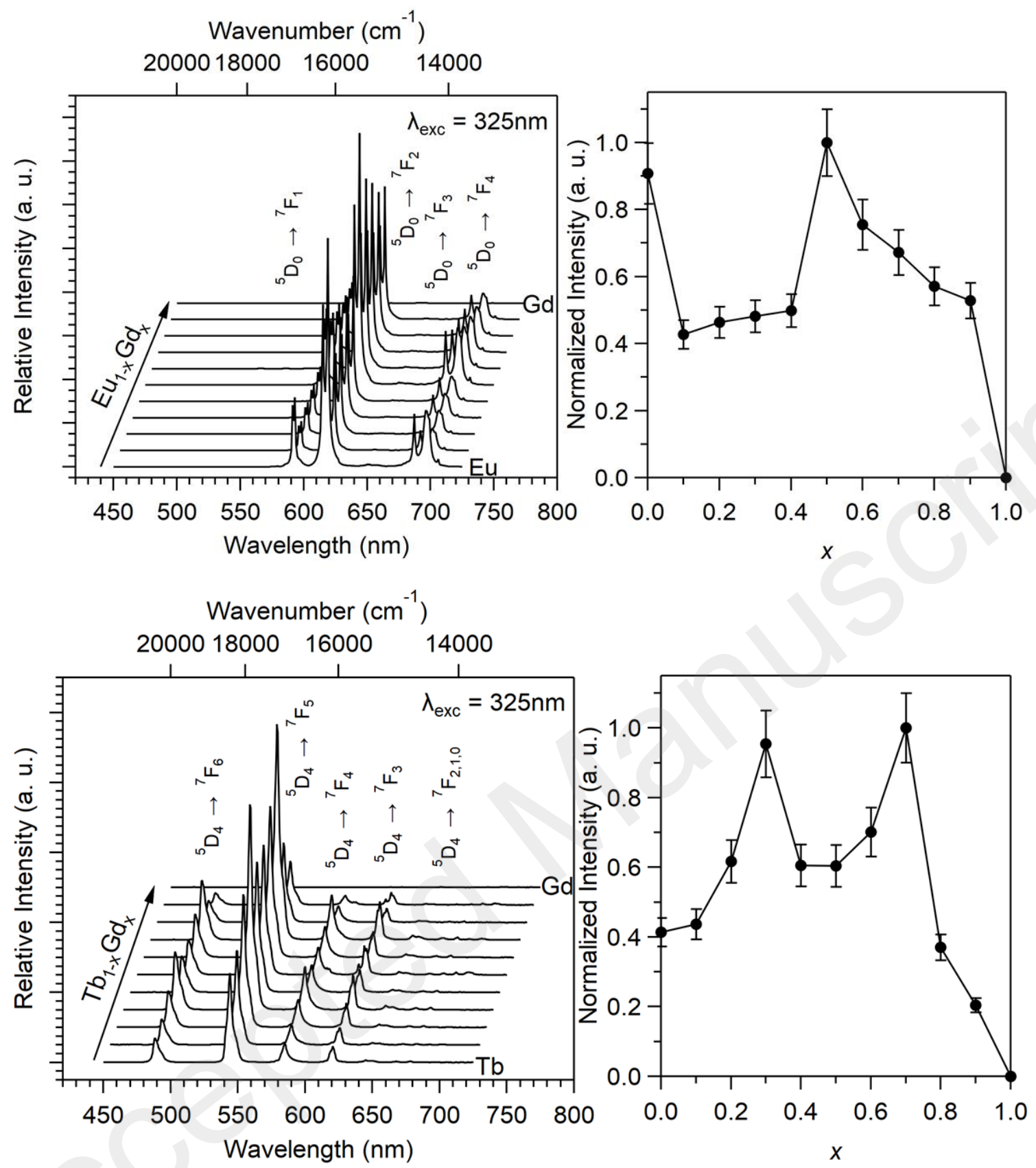

Figure 6. Solid-state emission spectra (left) and normalized integrated intensity of the major emission peak (right) for $\left[\mathrm{Eu}_{1-x} \mathrm{Gd}_{x} \text { (phen) }(\mathrm{glu})\left(\mathrm{NO}_{3}\right)\right]_{\infty}$ (top) and $\left[\mathrm{Tb}_{1-x} \mathrm{Gd}_{x}(\text { phen })(\mathrm{glu})\left(\mathrm{NO}_{3}\right)\right]_{\infty}$ (bottom) with $0 \leq x \leq 1 . \lambda_{\mathrm{exc}}=325 \mathrm{~nm}$.

For both series of compounds, the variation of the luminescence intensity versus $x$ does not present a standard behavior. Usually, the curve can be described as the result of the combination of two components: it first increases (as long as dilution effect is dominant because intermetallic quenching diminishes) and then decreases (because emitting centers become rare and dilution effect become less efficient). When the lanthanide distribution is 
isotropic enough (that is when only these two effects are relevant) the intensity maximum is observed exactly for the $x$ value that corresponds to a $10 \AA$ mean distance between the emitting centers (Scheme 2, left curve). ${ }^{21-22,42}$

To the best of our knowledge, the camel-back-like behaviors observed above have never been observed previously. Obviously, they cannot be attributed to the combination of only two phenomena. For the $\left[\mathrm{Eu}_{1-x} \mathrm{Gd}_{x}(\text { phen })(\mathrm{glu})\left(\mathrm{NO}_{3}\right)\right]_{\infty}$ series the camel-back behavior could arise from the combination of three phenomena: (i) the dilution effect; (ii) the decreasing of the emission intensity related to the decreasing of the number of emitting ions; (iii) the presence of dimers of emitting ions that induces intermetallic quenching. Before $x=0.5$, there is competition between a weak dilution effect (because the mean intermetallic distance in $\left[\mathrm{Eu}_{1}(\text { phen })(\mathrm{glu})\left(\mathrm{NO}_{3}\right)\right]_{\infty}$ is close to $\left.10 \AA\right)$, the decreasing of the number of emitting centers and a strong intra-dimer quenching. As evoked above, ${ }^{21,28,59}$ this effect is important if $x$ is small enough so that many emitting dimers are present. Statistically speaking, dimers don't exist anymore for $x=0.5$. This corresponds to a maximum in the luminance versus $x$ curve. Above $x=0.5$, the decreasing of the number of emitting ions becomes dominant and the luminance decreases again (Scheme 2, right curve).
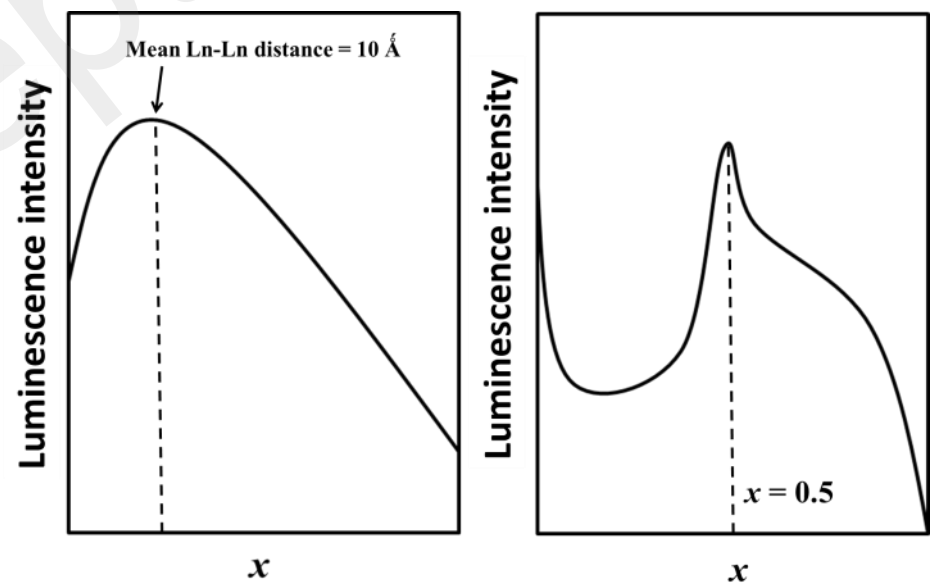

Scheme 2. Schematic representation of the standard luminescence intensity versus $x$ curve encountered usually (left) and of the observed intensity versus $x$ curve for the $\left[\mathrm{Eu}_{1-x} \mathrm{Gd}_{x}(\mathrm{phen})(\mathrm{glu})\left(\mathrm{NO}_{3}\right)\right]_{\infty}$ series (right). 
However, these topological considerations cannot explain the behavior of the curve observed for the $\left[\mathrm{Tb}_{1-x} \mathrm{Gd}_{x}(\text { phen })(\mathrm{glu})\left(\mathrm{NO}_{3}\right)\right]_{\infty}$ series because, if only topological effects were involved, the curves observed for the Eu- and Tb-based series of compounds would be similar. On another hand, it is commonly admitted that not only spatial overlap but also spectral overlap must be considered as far as energy transfers are concerned. ${ }^{18}$ This is a key point as we demonstrated that $\mathrm{Eu}^{3+}$ emitting energy levels can be fed efficiently by antenna effect while this is not the case for the $\mathrm{Tb}^{3+}$ ones (Scheme 1).

Back to the crystal structure, one can notice that there are pseudo-molecular-plane spreading parallel to the (ac)-plane based on dimeric units linked to each other by phen ligands $\pi$-stacking interactions. These interactions imply an overlap of the $\pi$-orbitals and therefore can allow electronic transfers. In the present case, because $\mathrm{Tb}^{3+}$ emitting excited states and ligand excited states are close in energy (Scheme 1), one can hypothesize that intermetallic energy transfers could arise between $\mathrm{Tb}^{3+}$ ions that belong to adjacent dimeric units (Scheme 3). Such loss of irradiating energy into internal energy transfer could also explain the unexpectedly weak intensity of the $\mathrm{Tb}$ derivatives when compared with the Eu ones in these series of compounds.

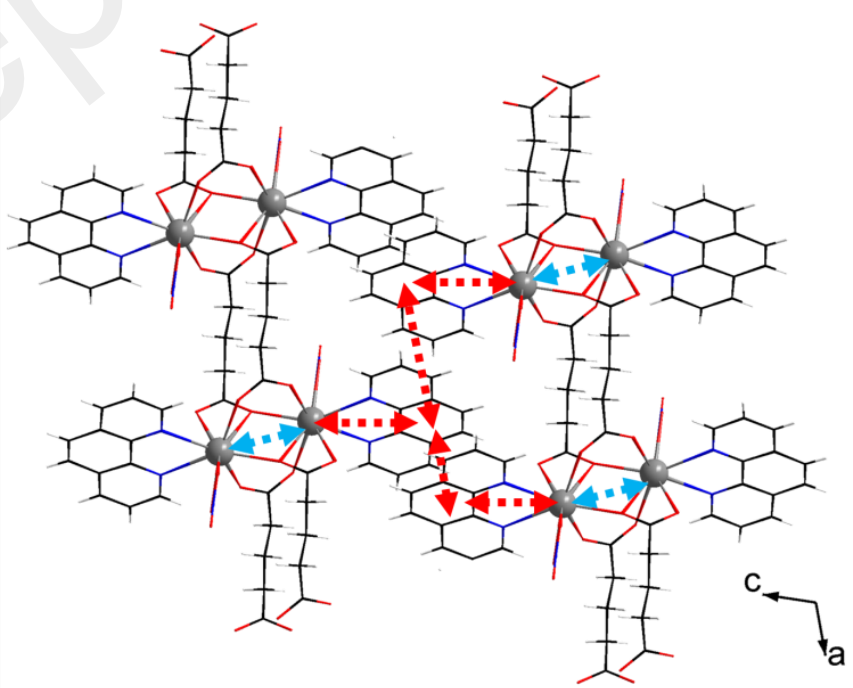

Scheme 3. Schematic energy transfers between lanthanide ions that belong to the same dimeric unit (blue arrows) and through phen ligands (red arrows). 
At this stage, it is difficult to predict the behavior of the luminescence intensity versus $x$ curve because it is hard to deconvolute the dependence versus $x$ of these four phenomena (dilution effect, diminution of the number of emitting centers, intramolecular intermetallic quenching in dimers and intermolecular intermetallic quenching). However, the presence of three extrema observed at $x \approx 1 / 3,1 / 2$ and $2 / 3$ are in agreement with this hypothesis. We believe that the study of the relative strengths of these four phenomena deserve to be studied in the future.

\section{Intermetallic energy transfers: $\left[\mathrm{Tb}_{1-x} \mathrm{Eu}_{x}(\text { phen })(\text { glu })\left(\mathrm{NO}_{3}\right)\right]_{\infty}$ with $0 \leq x \leq 1$}

In order to further explore inter-metallic energy transfer a third series of molecular alloys, with general chemical formula $\mathrm{Tb}_{1-x} \mathrm{Eu}_{x}($ phen $\left.)(\mathrm{glu})\left(\mathrm{NO}_{3}\right)\right]_{\infty}$ with $0 \leq x \leq 1$, has been prepared and characterized (Figure S2 and Table S1). The luminance of these compounds varies from 93 to $111 \mathrm{~cd} . \mathrm{m}^{-2}$ (Table S5). Emission spectra have been recorded and the integrated intensities of the major emission peaks of both $\mathrm{Eu}^{3+}$ and $\mathrm{Tb}^{3+}$ have been calculated (Figure 7).

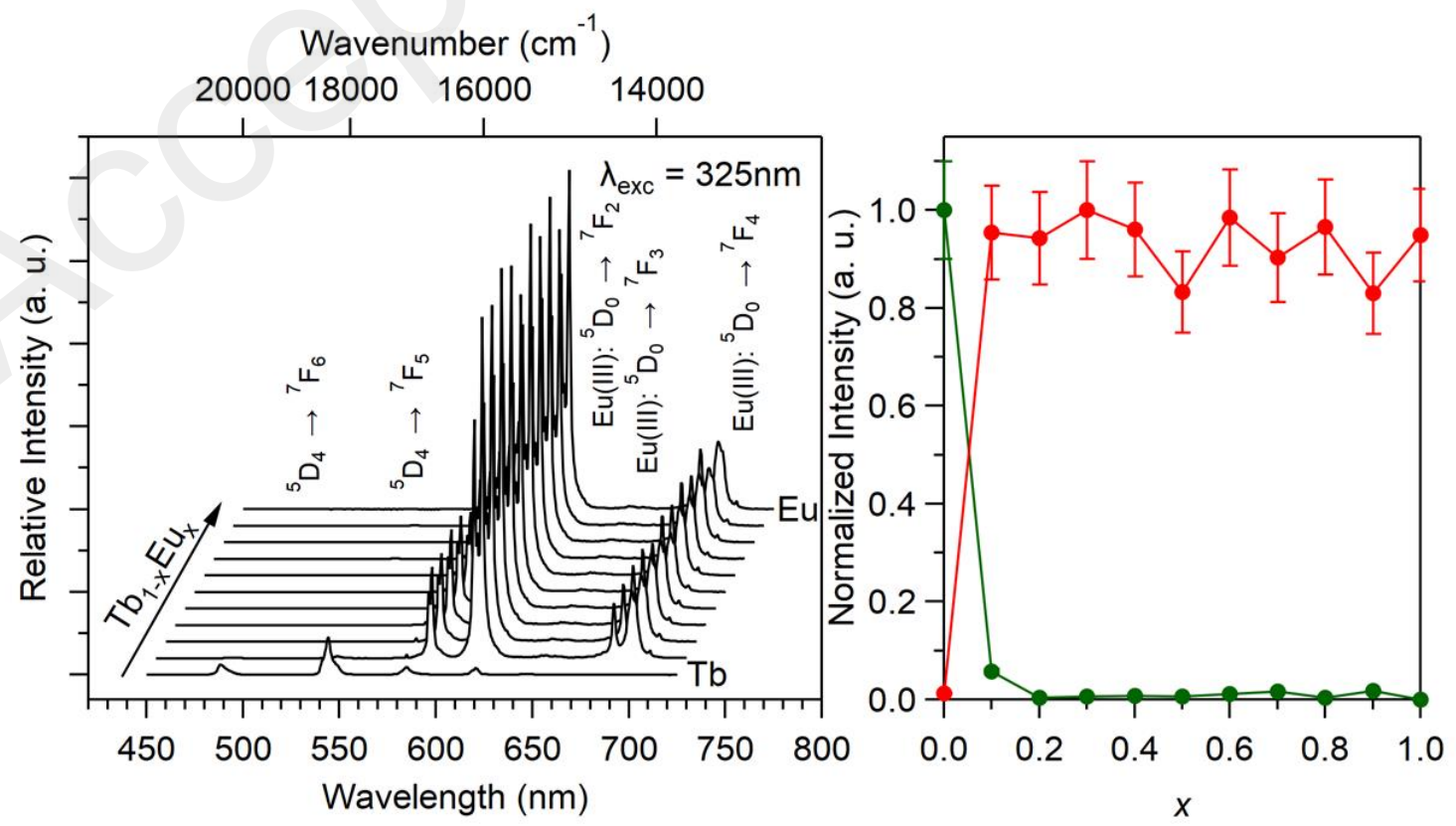


Figure 7. Solid-state emission spectra (left) and normalized integrated intensity of the major emission peak (right) for $\left[\mathrm{Tb}_{1-x} \mathrm{Eu}_{x} \text { (phen) }(\mathrm{glu})\left(\mathrm{NO}_{3}\right)\right]_{\infty}$ with $0 \leq x \leq 1 . \lambda_{\text {exc }}=325 \mathrm{~nm}$. Green circles correspond to the intensity of the major peak of $\mathrm{Tb}^{3+}$ and red circle to that of $\mathrm{Eu}^{3+}$.

Figure 7 evidences that integrated intensity of the $\mathrm{Eu}^{3+}$ is almost constant whatever $x$. Because of the complex behavior of both previous series, this was unexpected. $\eta_{\mathrm{ET}}$, the intermetallic energy efficiency, has been estimated for $\left[\mathrm{Tb}_{0.9} \mathrm{Eu}_{0.1}(\mathrm{phen})(\mathrm{glu})\left(\mathrm{NO}_{3}\right)\right]_{\infty}$ with the following relationship: ${ }^{18}$

$$
\eta_{\mathrm{ET}}=1-\frac{\tau_{\mathrm{obs}}}{\tau_{0}}
$$

Where $\tau_{\mathrm{obs}}$ and $\tau_{0}$ are the luminescence lifetimes of the $\mathrm{Tb}^{3+}$ ion measured in presence and in absence of the acceptor ion $\left(\mathrm{Eu}^{3+}\right)$, respectively, that is for $\left[\mathrm{Tb}_{0.9} \mathrm{Eu}_{0.1}(\mathrm{phen})(\mathrm{glu})\left(\mathrm{NO}_{3}\right)\right]_{\infty}$ $\left(\tau_{\mathrm{obs}}=14(1) \mu \mathrm{s}\right)$ and $\left[\mathrm{Tb}_{0.9} \mathrm{Gd}_{0.1}(\mathrm{phen})(\mathrm{glu})\left(\mathrm{NO}_{3}\right)\right]_{\infty}\left(\tau_{0}=0.20(1) \mathrm{ms}\right)$. According to this calculation, intermetallic efficiency is $93 \%$ which is in agreement with the very weak integrated intensity of $\mathrm{Tb}^{3+}$ observed in $\left[\mathrm{Tb}_{0.9} \mathrm{Gd}_{0.1}(\mathrm{phen})(\mathrm{glu})\left(\mathrm{NO}_{3}\right)\right]_{\infty}$.

\section{CONCLUSION AND OUTLOOKS.}

In this paper we have synthesized and structurally characterized a new family of homo- and hetero-lanthanide heteroleptic coordination polymers with general chemical formula $\left[\mathrm{Ln}(\text { phen })(\mathrm{glu})\left(\mathrm{NO}_{3}\right)\right]_{\infty}$ with $\mathrm{Ln}=\mathrm{Pr}-\mathrm{Yb}$ except Pm. Sizeable emissions under UV illumination and well resolved spectra where observed for $\mathrm{Pr}^{3+}, \mathrm{Nd}^{3+}, \mathrm{Sm}^{3+}, \mathrm{Eu}^{3+}, \mathrm{Tb}^{3+}, \mathrm{Dy}^{3+}$, $\mathrm{Ho}^{3+}, \mathrm{Er}^{3+}, \mathrm{Tm}^{3+}$ and $\mathrm{Yb}^{3+}$ derivatives. Because of energy back-transfer, the $\mathrm{Eu}^{3+}$ derivative is brighter than the $\mathrm{Tb}^{3+}$ one. ${ }^{75-76}$ Additionally, Eu- and Tb-based molecular alloys formed with the optically inactive $\mathrm{Gd}^{3+}$ ion, with general chemical formula $\left[\operatorname{Ln}_{1-x} \mathrm{Gd}_{x}(\text { phen })(\mathrm{glu})\left(\mathrm{NO}_{3}\right)\right]_{\infty}$, exhibit very different luminance. An unprecedented camel-back-like dependence of the luminance versus $x$ is observed as various energy transfer mechanism became dominant for a given $x$. On the $\mathrm{Eu}^{3+}$ series, the usual dilution effect (intermetallic quenching suppression) and diminution of the number of emitting centers are combined with intramolecular intermetallic 
quenching in dimers because emitting ions distribution is far from being isotropic in these compounds. On the $\mathrm{Tb}^{3+}$ series, these topological effects are completed by a fourth energy transfer that can be observed as intermolecular intermetallic quenching occurs. This work shows that lanthanide-based coordination polymers in which emitting centers are non isotropically distributed can give rise to unprecedented and very strong luminescence properties.

\section{ACKNOWLEDGMENTS}

The Algerian ministry of higher education and scientific research is acknowledged for a fellowship (PNE) to Roza Maouche.

\section{SUPPORTING INFORMATION.}

Experimental powder X-ray diffraction diagrams of compounds with general chemical formula $\left[\mathrm{Ln}(\mathrm{phen})(\mathrm{glu})\left(\mathrm{NO}_{3}\right)\right]_{\infty} \quad$ with $\mathrm{Ln}=\mathrm{La}-\mathrm{Yb}, \quad\left[\mathrm{Tb}_{1-x} \mathrm{Eu}_{x}(\mathrm{phen})(\mathrm{glu})\left(\mathrm{NO}_{3}\right)\right]_{\infty}$, $\left[\mathrm{Tb}_{1-x} \mathrm{Gd}_{x}(\text { phen })(\mathrm{glu})\left(\mathrm{NO}_{3}\right)\right]_{\infty}$ and $\left[\mathrm{Gd}_{1-x} \mathrm{Eu}_{x}(\text { phen })(\mathrm{glu})\left(\mathrm{NO}_{3}\right)\right]_{\infty}$ with $0 \leq x \leq 1 ;$ Metallic contents measured by EDS for $\left[\mathrm{Tb}_{1-x} \mathrm{Eu}_{x}(\text { phen })(\mathrm{glu})\left(\mathrm{NO}_{3}\right)\right]_{\infty},\left[\mathrm{Tb}_{1-x} \mathrm{Gd}_{x}(\mathrm{phen})(\mathrm{glu})\left(\mathrm{NO}_{3}\right)\right]_{\infty}$ and $\left[\operatorname{Gd}_{1-x} \mathrm{Eu}_{x}(\text { phen })(\mathrm{glu})\left(\mathrm{NO}_{3}\right)\right]_{\infty}$ with $0 \leq x \leq 1$; Selected bond lengths $(\AA)$ and angles $\left(^{\circ}\right)$ in $\left[\mathrm{La}(\text { phen })(\mathrm{glu})\left(\mathrm{NO}_{3}\right)\right]_{\infty} ;$ IR spectrum of $\left[\mathrm{La}(\text { phen })(\mathrm{glu})\left(\mathrm{NO}_{3}\right)\right]_{\infty} ; \mathrm{TG} / \mathrm{TD}$ analysis of $\left[\mathrm{La}(\text { phen })(\mathrm{glu})\left(\mathrm{NO}_{3}\right)\right]_{\infty} ;$ Solid-state absorption spectrum of $\left[\mathrm{La}(\mathrm{phen})(\mathrm{glu})\left(\mathrm{NO}_{3}\right)\right]_{\infty} ;$ Room temperature solid-state emission spectrum of $\left[\mathrm{La}(\mathrm{phen})(\mathrm{glu})\left(\mathrm{NO}_{3}\right)\right]_{\infty}$; Luminance versus $x$ of $\left[\mathrm{Gd}_{1-\mathrm{x}} \mathrm{Eu}_{\mathrm{x}}(\text { phen })(\mathrm{glu})\left(\mathrm{NO}_{3}\right)\right]_{\infty}$ and $\left[\mathrm{Tb}_{1-\mathrm{x}} \mathrm{Eu}_{\mathrm{x}}(\text { phen })(\mathrm{glu})\left(\mathrm{NO}_{3}\right)\right]_{\infty}$ with $0<\mathrm{x}<1$. 


\section{REFERENCES.}

1. Berg, E. W.; Alam, A., Studies on coordination polymers. Part I : Coordination polymers of 8,8'-dihydroxy-5,5'-biquinolyl. Anal. Chim. Acta 1962, 27, 454-459.

2. Bünzli, J. C. G., Rising stars in science and technology : Luminescent lanthanide materials. Eur. J. Inorg. Chem. 2017, 5058-5063.

3. Eliseeva, S. V.; Bünzli, J. C. G., Rare earths : jewels for functionnal materials of the future. New J. Chem. 2011, 35, 1165-1176.

4. $\quad$ Cui, Y.; Zhang, J.; Chen, B.; Qian, G., Lanthanide Metal-Organic Frameworks for Luminescent Applications. Handbook on the Physics and Chemistry of Rare Earths 2016, 50, 243-268.

5. Saraci, F.; Quezada-Novoa, V.; Donnarumma, P. R.; Howarth, A. J., Rare-earth metal-organic frameworks: from structure to applications. Chemical Society Reviews 2020, $10.1039 / \mathrm{d} 0 \mathrm{cs} 00292 \mathrm{e}$.

6. Brites, D. S. C.; Millan, A.; Carlos, L. D., Lanthanides in Luminescent Thermometry. In Handbook on the Physics and Chemistry of Rare Earths, Gschneidner, K. A.; Bünzli, J. C. G.; Pecharsky, V. K., Eds. Elsevier: 2016; Vol. 49, p 339-427.

7. Rocha, J.; Brites, D. S. C.; Carlos, L. D., Lanthanide organic framework luminescent thermometers. Chem. - Eur. J. 2016, 22, 14782-14795.

8. Gomez, G. E.; Marin, R.; Carneiro Neto, A. N.; Botas, A. M. P.; Ovens, J.; Kitos, A. A.; Bernini, M. C.; Carlos, L. D.; Soler-Illia, G. J. A. A.; Murugesu, M., Tunable EnergyTransfer Process in Heterometallic MOF Materials Based on 2,6-Naphthalenedicarboxylate: Solid-State Lighting and Near-Infrared Luminescence Thermometry. Chem. Mater. 2020, 32, 7458-7468.

9. Lustig, W. P.; Li, J., Luminescent metal organic frameworksand coordination polymers as alternative phosphors for energy efficient lighting devices. Coord. Chem. Rev. 2018, 373, 116-147.

10. Pan, M.; Liao, W.-M.; Yin, S.-Y.; Sun, S.-S.; Su, C.-Y., Single-Phase White-LightEmitting and Photoluminescent Color-Tuning Coordination Assemblies. Chemical Reviews 2018, 118, 8889-8935.

11. Eliseeva, S. V.; Bünzli, J. C. G., Lanthanide luminescence for functionnal materials and bio-sciences. Chem. Soc. Rev. 2010, 39, 189-227.

12. Bünzli, J.-C. G., Lanthanide luminescence for biomedical analyses and imaging. Chem. Rev. 2010, 111, 2729-2755.

13. Gamonal, A.; Sun, C.; Mariano, A. L.; Fernandez-Bartolome, E.; GuerreroSanVicente, E.; Vlaisavljevich, B.; Castells-Gil, J.; Marti-Gastaldo, C.; Poloni, R.; Wannemacher, R.; Cabanillas-Gonzalez, J.; Costa, J. S., Divergent Adsorption-Dependent Luminescence of Amino-Functionalized Lanthanide Metal-Organic Frameworks for Highly Sensitive NO2 Sensors. J. Phys. Chem. Lett. 2020, 11, 3362-3368.

14. He, J.; Xu, J.; Yin, J.; Li, N.; Bu, X.-H., Recent advances in luminescent metal-organic frameworks for chemical sensors. Science China Materials 2019, 62, 1655-1678.

15. He, H.; Chen, S.-H.; Zhang, D.-Y.; Hao, R.; Zhang, C.; Yang, E.-C.; Zhao, X.-J., A micrometer-sized europium(III)-organic framework for selective sensing of the $\mathrm{Cr} 2 \mathrm{O} 7^{2-}$ anion and picric acid in water systems. Dalton Trans. 2017, 46, 13502-13509.

16. Guillou, O.; Daiguebonne, C.; Calvez, G.; Bernot, K., A long journey in lanthanide chemistry : from fundamental crystallogenesis studies to commercial anti-counterfeiting taggants. Accounts Chem. Res. 2016, 49, 844-856. 
17. Gao, Z.; Xu, B.; Zhang, T.; Liu, Z.; Zhang, W.; Sun, X.; Liu, Y.; Wang, X.; Wang, Z.; Yan, Y.; Hu, F.; Meng, X.; Zhao, Y. S., Spatially Responsive Multicolor Lanthanide-MOF Heterostructures for Covert Photonic Barcodes. Angew. Chem. Int. Ed. 2020, 59, 1-6.

18. Bünzli, J. C. G.; Eliseeva, S. V., Basics of lanthanide photophysics. In Lanthanide Luminescence, Hänninen, P.; Härmä, H., Eds. Springer Berlin Heidelberg: 2010; Vol. 7, p 145.

19. Weissman, S. I., Intramolecular energy transfer - The fluorescence of complexes of europium. J. Chem Phys 1942, 10, 214-217.

20. Badiane, A. M.; Freslon, S.; Daiguebonne, C.; Suffren, Y.; Bernot, K.; Calvez, G.; Costuas, K.; Camara, M.; Guillou, O., Lanthanide based coordination polymers with a 4,5dichlorophthalate ligand exhibiting highly tunable luminescence : Toward luminescent bar codes. Inorg. Chem. 2018, 57, 3399-3410.

21. Badiane, I.; Freslon, S.; Suffren, Y.; Daiguebonne, C.; Calvez, G.; Bernot, K.; Camara, M.; Guillou, O., High britness and easy color modulation in lanthanide-based coordination polymers with 5-methoxyisophthalate as ligand: Toward emission colors additive strategy. Cryst. Growth Des. 2017, 17, 1224-1234.

22. Fan, X.; Freslon, S.; Daiguebonne, C.; Calvez, G.; Le Polles, L.; Bernot, K.; Guillou, O., Heteronuclear lanthanide-based coordination polymers exhibiting tunable multiple emission spectra. J. Mater. Chem. C 2014, 5510-5525.

23. Piguet, C.; Bünzli, J. C. G.; Bernardinelli, G.; Hopfgatner, G.; Williams, A. F., Selfassembly and photophysical properties of lanthanide dinuclear triple-helical complexes. $J$. Am. Chem. Soc. 1993, 115, 8197-8206.

24. Bünzli, J. C. G., On the design of highly luminescent lanthanide complexes. Coord. Chem. Rev. 2015, 293-294, 19-47.

25. Wang, J.; Daiguebonne, C.; Suffren, Y.; Roisnel, T.; Freslon, S.; Calvez, G.; Bernot, K.; Guillou, O., A new family of lanthanide-based coordination polymers with azoxybenzene3,3',5,5'-tetracarboxylic acid as ligand. Inorg. Chim. Acta 2019, 488, 208-213.

26. Pointel, Y.; Houard, F.; Suffren, Y.; Daiguebonne, C.; Le Natur, F.; Freslon, S.; Calvez, G.; Bernot, K.; Guillou, O., High luminance of hetero lanthanide based molecular alloys by phase-induction strategy. Inorg. Chem. 2020, 59, 11028-11040.

27. Chen, Y.; Huang, L.; Gao, R.; Chen, Y.; Huang, Z.; Zhang, W., Dy(III) and Sm(III) Coordination Polymers Based on 2,4-Pyridinedicarboxylic Acid: Synthesis, Structures, Luminescence and Magnetism. J. Clust. Sci. 2020, 10.1007/s10876-019-01706-5.

28. Abdallah, A.; Freslon, S.; Fan, X.; Rojo, A.; Daiguebonne, C.; Suffren, Y.; Bernot, K.; Calvez, G.; Roisnel, T.; Guillou, O., Lanthanide based coordination polymers with 1,4 carboxyphenylboronic ligand: multi emissive compounds for multi sensitive luminescent thermometric probes. Inorg. Chem. 2019, 58, 462-475.

29. Feng, X.; Shang, Y.; Zhang, H.; Li, R.; Wang, W.; Zhang, D.; Wang, L.; Li, Z., Enhanced luminescence and tunable magnetic properties of lanthanide coordination polymers based on fluorine substitution and phenanthroline ligand. RSC Advances 2019, 9, 1632816338.

30. Luo, Y.; Zheng, Y.; Calvez, G.; Freslon, S.; Bernot, K.; Daiguebonne, C.; Roisnel, T.; Guillou, O., Synthesis, crystal structure and luminescent properties of new lanthanidecontaining coordination polymers Involving 4,4'-oxy-bis-benzoate as Ligand. Cryst. Eng. Comm. 2013, 15, 706-720.

31. Maouche, R.; Belaid, S.; Benmerad, B.; Bouacida, S.; Freslon, S.; Daiguebonne, C.; Suffren, Y.; Calvez, G.; Bernot, K.; Roiland, C.; Le Polles, L.; Guillou, O., Luminescence properties of lanthanide complexes-based molecular alloys. Inorg. Chim. Acta 2020, 501, 119309. 
32. Zucchi, G.; Maury, O.; Thuéry, P.; Gumy, F.; Bünzli, J. C. G.; Ephritikhine, M., 2,2’Bipyrimidine as Efficient Sensitizer of the Solid-State Luminescence of Lanthanide and Uranyl Ions from Visible to Near-Infrared. Chem. - Eur. J. 2009, 15, 9686-9696.

33. Liu, X.; Zhou, J.; Zou, H.-H.; Fu, L., A 2-D dysprosium glutarate exhibiting slow magnetic relaxation and luminescent properties. J. Coord. Chem. 2018, 71, 2722-2731.

34. Zhang, L. P.; Wan, Y. H.; Jin, L. P., Hydrothermal synthesis and crystal structures of three novel lanthanide coordination polymers with glutarate and 1,10-phenantroline. J. Mol. Struc. 2003, 646, 169-178.

35. Wei, D. Y.; Xie, H. Z.; Huang, S. J.; Zhou, J.; Lu, G. X., Hydrothermal syntheses and characterization of four 2-Dysprosium coordination polymers with glutarate and 1,10phenantroline. J. Coord. Chem. 2011, 64, 424-430.

36. Jin, L.; Zhu, H. L., Poly $\left[\mu_{4}\right.$-glutarato-di- $\mu_{3}$-glutarato-bis $(1,10-$ phenantroline)diyttrium(III]. Acta Crystallogr. E 2011, E67, m1088.

37. Tan, X. F.; Zhou, J.; Zhou, H. H.; Fu, L.; Tang, Q.; Wang, A., A series of lanthanide glutarates: lanthanide contraction effect on crystal frameworks of lanthanide glutarates. RSC Advances 2017, 7, 17934-17940.

38. Xing, L.; Jian, Z.; Hua-Hong, Z.; Lianshe, F., A 2D dysprosium glutarateexhibiting slow magnetic relaxation and luminescent properties. J. Coord. Chem. 2018, 71, 2722-2731.

39. Maouche, R.; Belaid, S.; Benmerad, B.; Bouacida, S.; Daiguebonne, C.; Suffren, Y.; Guillou, O., A new praseodymium based coordination polymers with 1,10 phenantroline and glutarate ligands: Synthesis, crystal structure and luminescent properties. J. Mol. Struc. 2021, $1225,129164$.

40. Dechambenoit, P.; Ferlay, S.; Kyritsakas, N.; Hosseini, M. W., Playing with isostructurality : from tectons to molecular alloys and composite crystals. Chem. Comm. 2009, 1559-1561.

41. Desreux, J. F., In Lanthanide Probes in Life, Chemical and Earth Sciences, Choppin, G. R.; Bünzli, J. C. G., Eds. Elsevier: Amsterdam, 1989; Vol. Elsevier, p 43.

42. Haquin, V.; Etienne, M.; Daiguebonne, C.; Freslon, S.; Calvez, G.; Bernot, K.; Le Polles, L.; Ashbrook, S. E.; Mitchell, M. R.; Bünzli, J. C. G.; Guillou, O., Color and brightness tuning in hetero-nuclear lanthanide teraphthalate coordination polymers. Eur. $J$. Inorg. Chem. 2013, 3464-3476.

43. Fan, X.; Freslon, S.; Daiguebonne, C.; Le Polles, L.; Calvez, G.; Bernot, K.; Guillou, O., A family of lanthanide based coordination polymers with boronic acid as ligand. Inorg. Chem. 2015, 54, 5534-5546.

44. Kraus, W.; Nolze, G., POWDER CELL - A program for the representation and manipulation of crystal structures and calculation of the resulting X-ray powder patterns. $J$. Appl. Crystallogr. 1996, 29, 301-303.

45. Roisnel, T.; Rodriguez-Carjaval, J., A Window Tool for Powder Diffraction Patterns Analysis. J. Mater. Sci. Forum 2001, 378, 118-123.

46. Inc., B. A. SAINT, V837A; Brucker: Madison, Wisconsin, USA, 2014.

47. Altomare, A.; Burla, M. C.; Camalli, M.; Cascarano, G.; Giacovazzo, C.; Guagliardi, A.; Moliterni, A. G. G.; Polidori, G.; Spagna, R., SIR97: a new tool for crystal structure determination and refinement J. Appl. Crystallogr. 1999, 32, 115-119.

48. Sheldrick, G. M., A short history of SHELX. Acta Crystallogr. A 2008, 64, 112-122.

49. Farrugia, L. J., WinGX and ORTEP for Windows: an update. J. Appl. Crystallogr. 2012, 45, 849-854.

50. Huang, L.; Zhang, L., Hydrothermal synthesis and structural characterization of three novel lanthanide coordination polymers with fumarate and 1,10-phenantroline. J. Mol. Struc. 2004, 692, 249-253. 
51. Nakamoto, K., Infrared and raman spectra of inorganic and coordination compounds Part A: Theory and applications in inorganic chemistry, 6th edition. 6th edition ed.; John Wiley \& sons Inc: Hoboken, NJ, 2009.

52. Zhang, L.; Zhao, Y.; Qu, L.; Huang, L.; Wang, K.; Normal, A., Hydrothermal synthesis and structural characterization of three lanthanide coordination polymers with adipic acid and 1,10-phenantroline. J. Coord. Chem. 2008, 61, 2157-2166.

53. Li, X.; Zhang, Y.-B.; Zou, Y.-Q., Hydrothermel synthesis, crystal structure and luminescence of lanthanide(III) coordination polymers with tetrafluorosuccinate and 1,10phenantroline. J. Mol. Struc. 2009, 919, 277-283.

54. Kerbellec, N.; Kustaryono, D.; Haquin, V.; Etienne, M.; Daiguebonne, C.; Guillou, O., An Unprecedented Family of Lanthanide-Containing Coordination Polymers with Highly Tunable Emission Properties. Inorg. Chem. 2009, 48, 2837-2843.

55. CIE, International Commission on Illumination - Technical report. CIE: 1995; Vol. $13-3, \mathrm{p} 16$.

56. Wyszecki, G., Colorimetry. In Handbook of Optics, Driscoll, W. G.; Vaughan, W., Eds. Mac Graw-Hill Book Company: New-York, 1978, p 1-15.

57. Dexter, D. L., A theory of sensitized luminescence in solids. J. Chem. Phys. 1953, 21, 836-850.

58. Förster, T., Comparative effects of radiation. John Wiley \& Sons: New-York, 1960.

59. Rodrigues, M. O.; Dutra, J. D. L.; Nunes, L. A. O.; de Sa, G. F.; de Azevedo, W. M.; Silva, P.; Paz, F. A. A.; Freire, R. O.; Junior, S. A., $\mathrm{Tb}^{3+}->\mathrm{Eu}^{3+}$ energy transfer in mixed lanthanide organic frameworks. J. Phys. Chem. C 2012, 116, 19951-19957.

60. Freslon, S.; Luo, Y.; Daiguebonne, C.; Calvez, G.; Bernot, K.; Guillou, O., Brightness and color tuning in a series of lanthanide-based coordination polymers with benzene 1,2,4,5tetracarboxylic acid as ligand. Inorg. Chem. 2016, 55, 794-802.

61. Klink, S. I.; Hebbink, G. A.; Grave, L.; Oude Alink, P. G. B.; van Veggel, F. C. J. M., Synergistic Complexation of Eu3+ by a Polydentate Ligand and a Bidentate Antenna to

Obtain Ternary Complexes with High Luminescence Quantum Yields. Journal of Physical Chemistry A 2002, 106, 3681-3689.

62. Huo, R.; Li, X.; Ma, D., Lanthanide coordination frameworks constructed from 1,3benzenedicarboxylate, oxalate and 1,10-phenanthroline: crystal structure, multicolor luminescence and high-efficiency white light emission. CrystEngComm 2015, 17, 3838-3844. 63. Harbuzaru, B. V.; Corma, A.; Rey, F.; Jordá, J. L.; Ananias, D.; Carlos, L. D.; Rocha, J., A Miniaturized Linear pH Sensor Based on a Highly Photoluminescent Self-Assembled Europium(III) Metal-Organic Framework. Angewandte Chemie International Edition 2009, 48, 6476-6479.

64. Luo, Y.-H.; Yue, F.-X.; Yu, X.-Y.; Chen, X.; Zhang, H., Coordination polymers of lanthanide complexes with benzene dicarboxylato ligands. CrystEngComm 2013, 15, 63406348 .

65. Lahoud, M. G.; Frem, R. C. G.; Marques, L. F.; Arroyos, G.; Brandão, P.; Ferreira, R. A. S.; Carlos, L. D., A novel near monochromatic red emissive europium(III) metal-organic framework based on 1,2,4,5-benzenetetracarboxylate: From synthesis to photoluminescence studies. Journal of Solid State Chemistry 2017, 253, 176-183.

66. Harbuzaru, B. V.; Corma, A.; Rey, F.; Atienzar, P.; Jordá, J. L.; García, H.; Ananias, D.; Carlos, L. D.; Rocha, J., Metal-Organic Nanoporous Structures with Anisotropic Photoluminescence and Magnetic Properties and Their Use as Sensors. Angewandte Chemie International Edition 2008, 47, 1080-1083.

67. Silva, P.; Ananias, D.; Bruno, S. M.; Valente, A. A.; Carlos, L. D.; Rocha, J.; Almeida Paz, F. A., Photoluminescent Metal-Organic Frameworks - Rapid Preparation, Catalytic 
Activity, and Framework Relationships. European Journal of Inorganic Chemistry 2013, 2013, 5576-5591.

68. Luo, L.-L.; Qu, X.-L.; Li, Z.; Li, X.; Sun, H.-L., Isostructural lanthanide-based metalorganic frameworks: structure, photoluminescence and magnetic properties. Dalton transactions 2018, 47, 925-934.

69. Latva, M.; Takalo, H.; Mukkala, V.-M.; Matachescu, C.; Rodriguez-Ubis, J. C.; Kankare, J., Correlation between the lowest triplet state energy level of the ligand and lanthanide luminescence quantum yields. J. Lumin. 1997, 75, 149-169.

70. Carnall, W. T.; Fields, P. R.; Rajnak, K., Energy levels in the trivalent lanthanide ions. III. $\mathrm{Tb}^{3+}$. J. Chem. Phys. 1968, 49, 4447-4450.

71. Wong, K.-L.; Bünzli, J. C. G.; Tanner, P. A., Quantum yield and brightness. J. Lumin. 2020, 224, 117256.

72. Freslon, S.; Luo, Y.; Calvez, G.; Daiguebonne, C.; Guillou, O.; Bernot, K.; Michel, $\mathrm{V}$.; Fan, X., Influence of photo-induced electron transfer on lanthanide-based coordination polymers luminescence : A comparison between two pseudo-isoreticular molecular networks. Inorg. Chem. 2014, 53, 1217-1228.

73. Luo, Y.; Calvez, G.; Freslon, S.; Bernot, K.; Daiguebonne, C.; Guillou, O., Lanthanide amino-isophthalate coordination polymers. A promising system for tunable luminescent properties. Eur. J. Inorg. Chem. 2011, 3705-3716.

74. Pointel, Y.; Suffren, Y.; Daiguebonne, C.; Le Natur, F.; Freslon, S.; Calvez, G.; Bernot, K.; Guillou, O., Rational design of dual IR and visible highly luminescent light lanthanides based coordination polymers. Inorg. Chem. 2020, 59, 10673-10687.

75. Petoud, S.; Bünzli, J. C. G.; Glanzman, T.; Piguet, C.; Xiang, Q.; Thummel, R. P., Influence of charge-transfer states on the Eu(III) luminescence in mononuclear triple helical complexeswith tridentate aromatic ligands. J. Lumin. 1999, 82, 69-79.

76. Souza, A. S.; Nunes, L. A.; Felinto, M. C. F. C.; Brito, H. F.; Malta, O. L., On the quenching of trivalent terbium luminescence by ligand low lying triplet statee nergy and the role of the ${ }^{7} \mathrm{~F}_{5}$ level:The[Tb(tta) $\left.)_{3}\left(\mathrm{H}_{2} \mathrm{O}\right)_{2}\right]$ case. J. Lumin. 2015, 167, 167-171. 


\section{TABLE OF CONTENT}

A new series of lanthanide-based coordination polymers with highly luminescent $\mathrm{Eu}^{3+}$-derivatives.

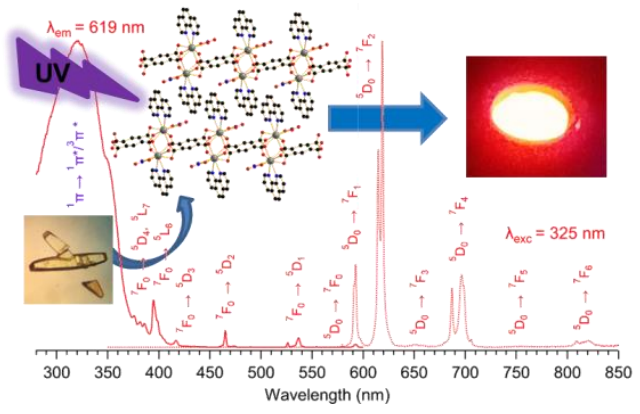

